\title{
Materials and Devices for Biodegradable and Soft Biomedical Electronics
}

\author{
Rongfeng $\mathrm{Li}^{\dagger}{ }^{\dagger}$, Liu Wang ${ }^{\dagger}$ and Lan Yin *(D) \\ School of Materials Science and Engineering, The Key Laboratory of Advanced Materials of Ministry of \\ Education, State Key Laboratory of New Ceramics and Fine Processing, Tsinghua University, \\ Beijing 100084, China; luckylrf@163.com (R.L.); liuwang@mail.tsinghua.edu.cn (L.W.) \\ * Correspondence: lanyin@tsinghua.edu.cn \\ + These authors contributed equally to this work.
}

Received: 3 October 2018; Accepted: 23 October 2018; Published: 26 October 2018

\begin{abstract}
Biodegradable and soft biomedical electronics that eliminate secondary surgery and ensure intimate contact with soft biological tissues of the human body are of growing interest, due to their emerging applications in high-quality healthcare monitoring and effective disease treatments. Recent systematic studies have significantly expanded the biodegradable electronic materials database, and various novel transient systems have been proposed. Biodegradable materials with soft properties and integration schemes of flexible or/and stretchable platforms will further advance electronic systems that match the properties of biological systems, providing an important step along the path towards clinical trials. This review focuses on recent progress and achievements in biodegradable and soft electronics for biomedical applications. The available biodegradable materials in their soft formats, the associated novel fabrication schemes, the device layouts, and the functionality of a variety of fully bioresorbable and soft devices, are reviewed. Finally, the key challenges and possible future directions of biodegradable and soft electronics are provided.
\end{abstract}

Keywords: biodegradable electronics; transient electronics; soft biomedical electronics; biodegradable materials

\section{Introduction}

With the growth of the global economy, and the development of science and technology, a massive assortment of electronics has been widely used in human society, which plays an important role in industrial processes, telecommunication, entertainment, healthcare, etc. [1-5]. Soft electronics that ensure conformal contact with nonplanar surfaces, such as soft biological tissues, are expected to play crucial roles in healthcare. The characteristic of these electronics is that they can significantly expand the capabilities of conventional rigid electronics in sensing, monitoring, diagnosing, and potentially intervening functions. The intimate contact between the soft device and the nonplanar object allows for high-quality data to be collected. Additionally, in the area of medical devices, soft electronics have similar mechanical properties to biological tissues and, thus, they cause minimal irritation to the human body.

On the other hand, biodegradable electronics possess unique characteristics and attract numerous research interests. The devices can dissolve, resorb, or physically disappear into physiological or environmental solutions, partially or completely, at controlled rates after the expecting working period [6-14]. Although long-lasting operation is one hallmark of traditional electronics, devices with biodegradability can potentially offer great benefits for temporary biomedical implants, green environmental electronics, and secured hardware. Biodegradable electronics can serve as temporary diagnostic and therapeutic platforms for important biological processes, e.g., wound healing 
and tissue regeneration, and they can be safely resorbed by the body after usage, eliminating a second surgery for device retrieval, and therefore avoiding associated infection risks and hospital costs [15]. Biodegradable electronics also provides an alternative way to alleviate issues that are associated with electronic waste (e-waste) [16], and they enable potential usage for security hardware, preventing unauthorized access of personal or security information [17,18].

Serving as medical implants, biodegradable electronics eliminate the potential retention of device materials, while soft electronics ensure conformal wrapping with the human body, as they are soft, curvilinear, and evolving [19]. Recent research on advanced materials [14], fabrication approaches [20], and design layouts [21] yield biodegradable and soft electronics that enable intimate integration into the body, with unique capabilities for diagnostic and therapeutic functions, which would otherwise be impossible when using conventional wafer-based electronics that are built upon non-degradable and rigid printed circuit boards. These emerging technologies provide critical tools that could have great potential to improve human health and enhance the understanding of biological systems.

This review specifically focuses on recent progress and achievements in electronics that combine both soft and biodegradable characteristics, targeting biomedical applications, while reviews on general transient electronics can be found elsewhere in references [6,13]. The available biodegradable materials in the soft formats, and their associated fabrication schemes are first reviewed, followed by the introduction of device layouts and the functionality of a variety of fully bioresorbable and soft devices, including solutions for power supply. Perspectives and the outlook of biodegradable soft electronics for clinical medicine are also provided at the end of the article.

\section{Materials}

A wide range of biodegradable materials have been explored to build biodegradable electronics. Traditional biodegradable materials are mostly based on polymers and magnesium alloys, and they serve mainly as structural components, e.g., cardiovascular stents and 3D scaffolds. As electronic properties are essential for constructing electronics, dissolvable inorganic materials with excellent operational characteristics are therefore also of great interest.

In addition to biodegradability, soft characteristics are another critical property to be considered for biomedical applications, in order to achieve minimal irritation to the body, and to obtain intimate contact with biological tissues. Soft materials should be able to survive mechanical deformations, and simultaneously, their functional properties should remain unaffected. The term "soft" can refer to flexible, foldable, stretchable, and twistable, and here, flexible materials are the focus.

The basic building blocks for electronic components are semiconductors, dielectrics, and conductors, and studies have developed strategies to ensure flexibility. The key method is to configure biodegradable inorganic semiconductors, dielectrics, and metals into thin film and open mesh formats, and to integrate them onto soft biodegradable polymeric or metal foil substrates. Through these techniques, biodegradable and flexible electronics that can adapt well to the soft nature of the human body.

In the following sections, inorganic biodegradable functional materials, substrate materials, and encapsulation materials, and organic functional materials will be reviewed respectively, in terms of their respective dissolution rates, mechanical properties, and biocompatibilities. Dissolution data from the literature of major inorganic materials are summarized in tables for better comparison. In all, dissolution rates of a wide range of biodegradable materials have been investigated in detail in simulated bio-fluids, such as phosphate-buffered saline (PBS), Hanks' solutions, artificial cerebrospinal fluid (ACSF), etc. A few studies have investigated the effects of proteins on the dissolution rates of Si. Strategies have been proposed to obtain soft biodegradable materials that combine both inorganic and organic components. Although detailed studies are needed to further reveal the pertinent biological influences, biodegradable materials of interest exhibit good biocompatibility through their evaluation in cell studies and animal trials. 


\subsection{Inorganic Functional Materials}

Functional materials are key components for electronics, and they consist of semiconductors, conductive materials, and dielectric materials. Inorganic dissolvable thin-film materials that have been explored, include monocrystalline silicon (mono-Si), polycrystalline silicon (poly-Si), amorphous silicon (a-Si), germanium (Ge), silicon germanium alloy (SiGe), indium-gallium-zinc oxide (a-IGZO), and zinc oxide ( $\mathrm{ZnO}$ ) [22-27] for semiconductors; magnesium (Mg), molybdenum (Mo), tungsten $(\mathrm{W})$, iron $(\mathrm{Fe})$, and zinc $(\mathrm{Zn})$ for conductive materials [23,27-29]; and magnesium oxide (MgO), silicon dioxide $\left(\mathrm{SiO}_{2}\right)$, and silicon nitride $\left(\mathrm{SiN}_{\mathrm{X}}\right)$ for dielectric materials $[14,20,30]$. The acceptable levels of these elements can be informed from nutritional supplements. The recommended dietary allowance and tolerable upper intake levels of functional materials are summarized in Table 1. As is shown, $\mathrm{Mg}, \mathrm{Mo}, \mathrm{Fe}$, and $\mathrm{Zn}$ are all necessary elements for the human body. It should be noticed that the mean intakes of $\mathrm{Si}$ in adult men and women are 40 and $19 \mathrm{mg}^{-1 a y}{ }^{-1}$ respectively, and limited toxicity research on Si suggests that there is no risk of inducing adverse effects for the general population, based on the common intake level [31].The mean total Ge exposure for people is $4 \mu \mathrm{g} \mathrm{day}^{-1}$, which can be absorbed from the intestinal tract and excreted largely through the kidneys [32-34]. In addition, $\mathrm{W}$ is usually found in rice, with concentrations of 7-283 $\mu \mathrm{g} \mathrm{kg}^{-1}$ [35]. However, because of a lack of adequate and sufficient data for $\mathrm{Si}, \mathrm{Ge}$, and $\mathrm{W}$, it is necessary to establish a recommended dietary allowance (RDA) and tolerable upper intake levels (UL).

Table 1. The recommended dietary allowance (RDA) and tolerable upper intake levels (UL) of biodegradable elements [31,36].

\begin{tabular}{cccccc}
\hline \multirow{2}{*}{ Life Stage } & \multirow{2}{*}{ Category } & \multicolumn{5}{c}{ Element } \\
\cline { 3 - 6 } & & $\mathbf{M g}(\mathbf{m g} /$ day) & Mo $(\mu \mathbf{g} /$ day) & Fe (mg/day) & Zn (mg/day) \\
\hline Infants & RDA & $30-75$ & $2-3$ & $0.27-11$ & $2-3$ \\
$0-12$ months & UL & - & - & 40 & $4-5$ \\
\hline Children & RDA & $80-130$ & $17-22$ & $7-10$ & $3-5$ \\
$1-8$ years & UL & $65-110$ & $300-600$ & 40 & $7-12$ \\
\hline Males & RDA & $240-420$ & $34-45$ & $8-11$ & $8-11$ \\
$\geq 9$ years & UL & 350 & $1100-2000$ & $40-45$ & $23-40$ \\
\hline Females & RDA & $240-320$ & $34-45$ & $8-15$ & $8-9$ \\
$\geq 9$ years & UL & 350 & $1100-2000$ & $40-45$ & $23-40$ \\
\hline Pregnancy & RDA & $350-400$ & 50 & 27 & $11-12$ \\
$14-50$ years & UL & 350 & $1700-2000$ & 45 & $34-40$ \\
\hline Lactation & RDA & $310-360$ & 50 & $9-10$ & $12-13$ \\
$14-50$ years & UL & 350 & $1700-2000$ & 45 & $34-40$ \\
\hline
\end{tabular}

Functional materials in the thin film format are adopted to assure flexibility, as well as reasonable degradation time frames. Studies have revealed that nanomembrane materials have high degrees of bendability, as the flexural rigidity and energy release rates scale down with thickness, enabling an intimate contact with non-planar and curvilinear surface [37]. Nanomembranes can be obtained by peeling the top membrane materials from commercially available wafers (e.g., silicon on insulator, SOI), which will be discussed later. Low-temperature deposition such as radiofrequency plasma-enhanced chemical vapor deposition (RF-PECVD) [38], electron cyclotron resonance (ECR) [39], and hot-wire chemical vapor deposition (HW-CVD) [40] can be used to fabricate high-quality functional thin films directly onto soft substrates. Additionally, solution-printing techniques have also been proposed as a low-cost alternative methods [41]. Another robust strategy for achieving soft materials is through structural design, which not only enhances the flexibility of intrinsic soft materials, but also gives flexibility to materials that are intrinsically rigid. Methods include separating rigid thin film materials 
into small islands, introducing serpentine, wavy, buckled interconnects, integrating rigid materials with soft substrates, etc. [42,43].

The research on silicon nanomembrane (Si NM) dissolution behavior greatly promotes the development of transient electronics, as it can leverage existing well-established Si semiconductor technology and realize high-performance biodegradable electronics. The dissolution rates of $\mathrm{Si}$ NMs in solutions with different ionic types and relevant concentrations [23,24], temperatures [24], $\mathrm{pH}$ values [23], concentrations of protein [44], as well as doping levels [22] have been investigated, all of which play an important role during the silicon dissolution process. The dissolution rates of $\mathrm{Si}$ NMs under different conditions are tabulated in Table 2. For example, dissolution rates have been observed for Si NMs (slightly p-doped $10^{-17} \mathrm{~cm}^{-3}, 100$ orientation) in aqueous solutions containing various chloride and phosphate concentrations at different temperatures. Higher temperatures and concentrations of chlorides and phosphates can greatly promote Si dissolution, probably through a nucleophilic dissolution process [24]. The underlying mechanism regarding the influence of chlorides and phosphates has been evaluated through density functional theory (DFT) and molecular dynamics (MD) simulations [24]. Dissolution rates of Si are found to be sensitive to calcium and magnesium ions as well [44]; e.g., the addition of $1 \mathrm{mM}$ of $\mathrm{Ca}^{2+}$ and $\mathrm{Mg}^{2+}$ can slightly increase the rates in phosphate buffered saline solutions. As shown in Table 2, the presence of albumin decelerates the dissolution rates, probably due to the absorption of the protein onto the Si surface [44]. In addition, the types and concentrations of dopants for Si NMs can affect the dissolution rate significantly, and a sharp decrease in dissolution rate can be found when dopant concentrations exceed a certain level, i.e., $10^{20} \mathrm{~cm}^{-3}$.

Similarly, dissolution rates of poly-Si, a-Si, alloys of silicon, $\mathrm{SiGe}$, and $\mathrm{Ge}$ show great dependence on the $\mathrm{pH}$, temperatures, proteins, and type of ions [26]. For instance, the rates of these materials at physiological temperatures $\left(37^{\circ} \mathrm{C}\right)$ are higher than those at room temperature. At similar $\mathrm{pHs,}$ bovine serum leads to dissolution rates at $37^{\circ} \mathrm{C}$ that are $30-40$ times higher than those of a phosphate buffer solution for poly-Si, a-Si, and nano-Si. For SiGe, the dissolution rate exhibits an even more strongly accelerated rate ( 185 times) in bovine serum. Besides $\mathrm{Si}$ and $\mathrm{SiGe}$, dissolution rates of Ge and two-dimensional (2D) $\mathrm{MoS}_{2}$ materials have also been evaluated in physiological solutions, and the dissolution rates are summarized in Table 3. The dissolution of monolayer $\mathrm{MoS}_{2}$ crystals in PBS occurs as a defect-induced etching progress, in which the grain boundaries dissolve first, followed by the crystalline regions. Moreover, the increased concentrations of $\mathrm{Na}^{+}$and $\mathrm{K}^{+}$accelerate the degradation, because the existence of $\mathrm{Na}^{+}$or $\mathrm{K}^{+}$leads to lattice distortions of $\mathrm{MoS}_{2}$ and the formation of $\mathrm{Na}_{2} \mathrm{~S}$.

Table 2. The dissolution behavior of silicon nanomembranes (Si NMs) under different conditions $[22-24,26,44]$.

\begin{tabular}{|c|c|c|c|c|c|}
\hline $\begin{array}{l}\text { Functional } \\
\text { Materials }\end{array}$ & Temperature ${ }^{\circ} \mathrm{C}$ & Aqueous Solution & $\mathrm{pH}$ & Doping Type $\mathrm{cm}^{-3}$ & $\begin{array}{c}\text { Dissolution Rate } \\
\text { nm day }^{-1}\end{array}$ \\
\hline \multirow{16}{*}{ Mono-Si NMs [24] } & \multirow{8}{*}{37} & Phosphate $0.05 \mathrm{M}$ & \multirow{8}{*}{7.5} & \multirow{8}{*}{$10^{17}(\mathrm{p})$} & 2.512 \\
\hline & & Phosphate $0.1 \mathrm{M}$ & & & 25.119 \\
\hline & & Phosphate $0.5 \mathrm{M}$ & & & 50.119 \\
\hline & & Phosphate $1 \mathrm{M}$ & & & 63.096 \\
\hline & & Chloride $0.05 \mathrm{M}$ & & & 1.259 \\
\hline & & Chloride $0.1 \mathrm{M}$ & & & 6.309 \\
\hline & & Chloride $0.5 \mathrm{M}$ & & & 63.096 \\
\hline & & Chloride $1 \mathrm{M}$ & & & 63.096 \\
\hline & \multirow{8}{*}{50} & Phosphate $0.05 \mathrm{M}$ & \multirow{8}{*}{7.5} & \multirow{8}{*}{$10^{17}(\mathrm{p})$} & 3.162 \\
\hline & & Phosphate $0.1 \mathrm{M}$ & & & 31.623 \\
\hline & & Phosphate $0.5 \mathrm{M}$ & & & 125.893 \\
\hline & & Phosphate $1 \mathrm{M}$ & & & 251.189 \\
\hline & & Chloride $0.05 \mathrm{M}$ & & & 5.012 \\
\hline & & Chloride $0.1 \mathrm{M}$ & & & 15.849 \\
\hline & & Chloride $0.5 \mathrm{M}$ & & & 199.526 \\
\hline & & Chloride $1 \mathrm{M}$ & & & 398.107 \\
\hline
\end{tabular}


Table 2. Cont.

\begin{tabular}{|c|c|c|c|c|c|}
\hline $\begin{array}{l}\text { Functional } \\
\text { Materials }\end{array}$ & Temperature ${ }^{\circ} \mathrm{C}$ & Aqueous Solution & $\mathrm{pH}$ & Doping Type $\mathrm{cm}^{-3}$ & $\begin{array}{l}\text { Dissolution Rate } \\
\text { nm day }\end{array}$ \\
\hline \multirow{9}{*}{ Mono-Si NMs [22] } & \multirow{3}{*}{37} & \multirow{3}{*}{ Buffer solution $0.1 \mathrm{M}$} & \multirow{3}{*}{7.4} & $10^{17}(\mathrm{p})$ & 3.162 \\
\hline & & & & $10^{19}(\mathrm{p})$ & 3.162 \\
\hline & & & & $10^{20}(\mathrm{p})$ & 0.501 \\
\hline & \multirow{3}{*}{37} & \multirow{3}{*}{ Buffer solution $0.1 \mathrm{M}$} & \multirow{3}{*}{7.4} & $10^{17}(\mathrm{~b})$ & 3.162 \\
\hline & & & & $10^{19}(\mathrm{~b})$ & 3.162 \\
\hline & & & & $10^{20}(\mathrm{~b})$ & 0.251 \\
\hline & Room temperature (RT) & Coke & 2.6 & - & 0.600 \\
\hline & RT & Milk & 6.4 & - & 23.300 \\
\hline & RT & PBS $0.1 \mathrm{M}$ & 7.4 & - & 1.820 \\
\hline \multirow{2}{*}{ Mono-Si NMs [23] } & \multirow{2}{*}{37} & Bovine serum & 7.4 & - & 100.800 \\
\hline & & Sea water & 7.8 & - & 4.115 \\
\hline \multirow{28}{*}{ Mono-Si NMs [44] } & \multirow{3}{*}{37} & Albumin phosphate & \multirow{3}{*}{7.4} & \multirow{3}{*}{$10^{15}(\mathrm{~b})$} & 42.100 \\
\hline & & $\begin{array}{l}\text { buffered saline (PBS) } \mathrm{Na}^{+} \\
\text {Albumin PBS } \mathrm{Mg}^{2+}\end{array}$ & & & 45.010 \\
\hline & & Albumin PBS Ca ${ }^{2+}$ & & & 51.000 \\
\hline & \multirow[b]{2}{*}{20} & \multirow[b]{2}{*}{ Purified water } & \multirow[b]{2}{*}{5.5} & $10^{15}(\mathrm{~b})$ & $<0.010$ \\
\hline & & & & $10^{20}(\mathrm{~b})$ & $<0.010$ \\
\hline & \multirow[b]{2}{*}{20} & \multirow{2}{*}{ Tap water } & & $10^{15}(\mathrm{~b})$ & 0.710 \\
\hline & & & 7.5 & $10^{20}(\mathrm{~b})$ & 0.420 \\
\hline & & & & $10^{15}(\mathrm{~b})$ & 21.020 \\
\hline & 37 & Serum & 7.4 & $10^{20}(\mathrm{~b})$ & 0.500 \\
\hline & & Hank's balanced salt & & $10^{15}(\mathrm{~b})$ & 58.010 \\
\hline & 37 & solution (HBSS) & 7.6 & $10^{20}(\mathrm{~b})$ & 7.010 \\
\hline & & HBSS $/ C_{2} \mathrm{Mr}$ & & $10^{15}(\mathrm{~b})$ & 66.020 \\
\hline & 37 & HDSs w/ Ca, Mg & 7.6 & $10^{20}(\mathrm{~b})$ & 8.020 \\
\hline & & HBSS & & $10^{15}(\mathrm{~b})$ & 129.030 \\
\hline & 37 & HBSS & 8.2 & $10^{20}(\mathrm{~b})$ & 58.000 \\
\hline & & & & $10^{15}(\mathrm{~b})$ & 178.000 \\
\hline & 37 & HBSS w/Ca, Mg & 8.2 & $10^{20}(\mathrm{~b})$ & 69.010 \\
\hline & & Purified water & 5.5 & & 0.010 \\
\hline & 20 & Tap water & 7.5 & $10^{15}(\mathrm{~b})$ & 0.720 \\
\hline & & Serum & 7.4 & & 3.500 \\
\hline & & Purified water & 5.5 & & 0.210 \\
\hline & & Tap water & 7.5 & & 2.620 \\
\hline & & Sweat & 4.5 & & 0.530 \\
\hline & & Serum & 7.4 & & 21.000 \\
\hline & 37 & HBSS & 7.6 & $10^{15}(\mathrm{~b})$ & 58.210 \\
\hline & & HBSS w/Ca, Mg & 7.6 & & 66.010 \\
\hline & & HBSS & 8.2 & & 129.020 \\
\hline & & HBSS w/Ca, Mg & 8.2 & & 178.000 \\
\hline & & & 7 & - & 1.020 \\
\hline & & & 7.4 & & 1.585 \\
\hline & RT & Buffer solution & 8 & & 10.010 \\
\hline 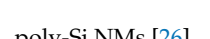 & & & 10 & & 398.107 \\
\hline pory-Si Nivis [20] & & & 7 & - & 1.259 \\
\hline & & & 7.4 & & 3.162 \\
\hline & 37 & Buffer solution & 8 & & 19.953 \\
\hline & & & 10 & & 562.341 \\
\hline & & & 7 & - & 1.778 \\
\hline & & & 7.4 & & 3.981 \\
\hline & RT & Buffer solution & 8 & & 15.849 \\
\hline -Si NMs [26] & & & 10 & & 501.187 \\
\hline$a^{-3}-31$ Nivis $[20]$ & & & 7 & - & 1.585 \\
\hline & & & 7.4 & & 5.011 \\
\hline & 37 & Buffer solution & 8 & & 31.623 \\
\hline & & & 10 & & 630.957 \\
\hline
\end{tabular}

Note: $\mathrm{p}$ stands for phosphate doping, and $\mathrm{b}$ stands for boron doping. 
Table 3. The dissolution behavior of Ge and 2D MoS 2 under different conditions [26,45].

\begin{tabular}{|c|c|c|c|c|}
\hline $\begin{array}{l}\text { Functional } \\
\text { Materials }\end{array}$ & Temperature ${ }^{\circ} \mathrm{C}$ & Aqueous Solution & $\mathrm{pH}$ & $\begin{array}{l}\text { Dissolution Rate } \\
\text { nm day }^{-1}\end{array}$ \\
\hline \multirow{8}{*}{ Ge [26] } & \multirow{4}{*}{ RT } & \multirow{4}{*}{ Aqueous Buffer solution } & 7 & 0.794 \\
\hline & & & 7.4 & 1.995 \\
\hline & & & 8 & 15.849 \\
\hline & & & 10 & 501.187 \\
\hline & \multirow{4}{*}{37} & \multirow{4}{*}{ Aqueous Buffer solution } & 7 & 1.259 \\
\hline & & & 7.4 & 3.162 \\
\hline & & & 8 & 19.953 \\
\hline & & & 10 & 562.341 \\
\hline \multirow{8}{*}{ Poly-MoS 2 [45] } & \multirow{2}{*}{40} & \multirow{2}{*}{ 1.0 M PBS } & 7.4 & 0.010 \\
\hline & & & 12 & 0.010 \\
\hline & \multirow{2}{*}{60} & \multirow{2}{*}{ 1.0 M PBS } & 7.4 & 0.070 \\
\hline & & & 12 & 0.160 \\
\hline & \multirow[b]{2}{*}{75} & \multirow[b]{2}{*}{ 1.0 M PBS } & 7.4 & 0.200 \\
\hline & & & 12 & 0.270 \\
\hline & \multirow[b]{2}{*}{85} & \multirow{2}{*}{$1.0 \mathrm{M}$ PBS } & 7.4 & 0.270 \\
\hline & & & 12 & 0.400 \\
\hline
\end{tabular}

Metals related to trace elements that are normally found in human body, such as $\mathrm{Mg}, \mathrm{Zn}, \mathrm{W}$, $\mathrm{Fe}, \mathrm{Mo}$, and their oxides, are great candidates for interconnects and dielectric materials [23,29,46]. Strain-tolerant metallic thin films can be fabricated by electron-beam deposition, pulsed-laser deposition, or magnetron sputtering, following photolithography. Among them, $\mathrm{Mg}$ and $\mathrm{Zn}$ are utilized more frequently, owing to the easy processing property and better concentration tolerance for patients, which means lower costs and safer resorbable properties. However, the degradation rates of $\mathrm{Mg}$ and $\mathrm{Zn}$ are relative fast; metals with slower rates $(\mathrm{W}, \mathrm{Mo})$ are, therefore, more desirable if a longer life time is needed [29]. Fe thin films become rusted easily, and they are converted to iron oxides and hydroxides, which have extremely lower solubilities in neutral solutions, and slightly acidic environments are probably more desirable for inducing complete degradation [29].

Moreover, dielectric materials, including magnesium oxide $(\mathrm{MgO})$, silicon dioxide $\left(\mathrm{SiO}_{2}\right)$, silicon nitride $\left(\mathrm{Si}_{3} \mathrm{~N}_{4}\right)$, and spin-on-glass $(\mathrm{SOG})$, are also dissolvable in aqueous solutions. The dissolution rates of these materials depend not only on $\mathrm{pHs}$, temperatures, and ion concentrations, but also on the physical and chemical properties of the films, which are affected by the deposition condition $[10,14,47]$. For example, the dissolution rates of oxides deposited by electron-beam (e-beam) evaporation are 100 times slower compared to those deposited by plasma-enhanced chemical vapor deposition (PECVD). For nitrides, the dissolution rate of a low-pressure chemical vapor deposition (LPCVD) nitride is slower than that of a PECVD nitride. The degradation rates of metals and dielectric materials are summarized in Tables 4 and 5, respectively.

Table 4. Dissolution behavior of metals [47-51].

\begin{tabular}{cccc}
\hline Functional Materials & Test Conditions & $\begin{array}{c}\text { Dissolution Rate } \\
\text { nm day }\end{array}$ & Dissolution Product \\
\hline Mg [48] & Deionized water, RT & 1680.000 & $\mathrm{Mg}(\mathrm{OH})_{2}$ \\
$\mathrm{Zn} \mathrm{[49]}$ & Deionized water, RT & 168.000 & $\mathrm{Zn}(\mathrm{OH})_{2}$ \\
Fe [47] & Simulated body fluids, 37 ${ }^{\circ} \mathrm{C}$ & $5.000-80.000$ & $\mathrm{Fe}(\mathrm{OH})_{2}, \mathrm{Fe}(\mathrm{OH})_{3}$ \\
Mo [50] & Deionized water, RT & 7.200 & $\mathrm{H}_{2} \mathrm{MoO}{ }_{4}$ \\
W [51] & Deionized water, RT & $7.200-3.000-40.800$ & $\mathrm{H}_{2} \mathrm{WO}_{4}$ \\
\hline
\end{tabular}


Table 5. Dissolution behaviors of dielectric materials in buffer solution at $37^{\circ} \mathrm{C}[10,47]$.

\begin{tabular}{|c|c|c|c|c|}
\hline $\begin{array}{l}\text { Functional } \\
\text { Materials }\end{array}$ & $\begin{array}{l}\text { Fabrication } \\
\text { Methods }\end{array}$ & Test Conditions & $\begin{array}{l}\text { Dissolution Rate } \\
\text { nm day }\end{array}$ & $\begin{array}{l}\text { Dissolution } \\
\text { Product }\end{array}$ \\
\hline \multirow{3}{*}{$\mathrm{SiO}_{2}[10]$} & E-beam & $37^{\circ} \mathrm{C}$ & 10.000 & \multirow{3}{*}{$\mathrm{Si}(\mathrm{OH})_{4}$} \\
\hline & PECVD & $37^{\circ} \mathrm{C}$ & 0.100 & \\
\hline & Thermally grown & $37^{\circ} \mathrm{C}$ & 0.003 & \\
\hline \multirow{12}{*}{$\mathrm{Si}_{3} \mathrm{~N}_{4}[10]$} & LPCVD & $\mathrm{pH} 7.4$ & 0.158 & \multirow{12}{*}{$\mathrm{Si}(\mathrm{OH})_{4}+\mathrm{NH}_{3}$} \\
\hline & LPCVD & $\mathrm{pH} 8$ & 0.251 & \\
\hline & LPCVD & pH 10 & 0.316 & \\
\hline & LPCVD & $\mathrm{pH} 12$ & 0.631 & \\
\hline & PECVD-LF & $\mathrm{pH} 7.4$ & 0.794 & \\
\hline & PECVD-LF & $\mathrm{pH} 8$ & 1.585 & \\
\hline & PECVD-LF & $\mathrm{pH} 10$ & 1.995 & \\
\hline & PECVD-LF & $\mathrm{pH} 12$ & 3.981 & \\
\hline & PECVD-HF & $\mathrm{pH} 7.4$ & 0.794 & \\
\hline & PECVD-HF & $\mathrm{pH} 8$ & 2.512 & \\
\hline & PECVD-HF & $\mathrm{pH} 10$ & 6.310 & \\
\hline & PECVD-HF & $\mathrm{pH} 12$ & 25.119 & \\
\hline \multirow{2}{*}{$\begin{array}{l}\text { Spin-on glass } \\
\text { (SOG) [47] }\end{array}$} & cured at $300^{\circ} \mathrm{C}$ & PBS, pH 7.4 & 50.000 & \multirow{2}{*}{$\mathrm{Si}(\mathrm{OH})_{4}$} \\
\hline & cured at $800^{\circ} \mathrm{C}$ & PBS, pH 7.4 & 6.000 & \\
\hline
\end{tabular}

Figure 1a shows the representative flexible circuit based on dissolvable inorganic Si electronic materials on silk substrate, including transistors made by $\mathrm{Si} / \mathrm{MgO} / \mathrm{Mg}$, diodes made by $\mathrm{Si}$, and inductors and capacitors made by $\mathrm{Mg} / \mathrm{MgO}$, as well as resistor and connection wires made by $\mathrm{Mg}$. The related transience properties in the operational characteristics of $\mathrm{n}$-channel transistors are shown on the left side, which are comparable with transistors that are built with non-dissolvable materials. Logic circuits can be built based on the transistor unit cells, which provide a promising path to achieving soft and biodegradable multi-functional $\mathrm{Si}$ electronics [14]. Figure $1 \mathrm{~b}$ illustrates a transient circuit composed of $\mathrm{Ga}_{2} \mathrm{O}_{3} / \mathrm{In}_{2} \mathrm{O}_{3} / \mathrm{ZnO}$ thin film transistors (TFTs), with transfer performance with widths $(\mathrm{W}) /$ lengths $(\mathrm{L})(=30 / 10 \mu \mathrm{m})$. The output feature corresponds to a 0 to $10 \mathrm{~V}$ gate bias, with a step of $2 \mathrm{~V}$, for 0 to $5 \mathrm{~V}$ drain bias ( $\mathrm{V}_{\mathrm{DS}}$ ) [27], which represents an alternative inorganic semiconductor for soft transient electronics. In Figure 1c, W powders are integrated onto a flexible sodium carboxymethyl cellulose $(\mathrm{Na}-\mathrm{CMC})$ substrate to print a temperature sensor circuit with a sensing performance that is closed to the weather report, which indicates an alternative method for quickly achieving biodegradable circuits [28]. Two-dimensional materials, such as $\mathrm{MoS}_{2}$, with attractive optical, electrical, and mechanical properties, have also been explored, to form biodegradable electronics. Figure $1 \mathrm{~d}$ shows a transient pressure sensor that is integrated with Mo and $\mathrm{MoS}_{2}$ as the functional materials, which can be utilized to prepare a temperature sensor in vivo. Meanwhile, the literature suggests that $\mathrm{MoS}_{2}$ can gradually dissolve in PBS solution $(\mathrm{pH}=7.4)$ at $75^{\circ} \mathrm{C}$, which may be adjusted by changing the grain size [45]. This investigation offers new insights incorporating ultrathin 2D materials for bioresorbable devices.

The biocompatibility of the materials and the products of their dissolution are important for applications in bioresorbable electronics. In vitro cytotoxicity studies on mono-Si, poly-Si, $\alpha-\mathrm{Si}, \mathrm{SiGe}$, and $\mathrm{Ge}$, with both neighboring stromal fibroblast cells and infiltrating immune cells, suggest that both of these materials and their dissolution products are biocompatible [26]. In addition, in vivo evaluations of Si NMs implanted into the subdermal regions of an albino, laboratory-bred strain of the house mouse (BALB/c mice), show that following five weeks of implantation, immunoprofiling of lymphocytes from the peripheral blood and draining lymph nodes revealed no significant differences in the percentages of CD4+ and CD8+ T cells for implanted animals and sham-operated controls, which suggests long-term immunological and tissue biocompatibility [23]. Furthermore, an in vitro assessment of cytotoxicity on a patterned array of Si NMs using cells from a metastatic breast cancer cell line (MAD-MB-231), and in vivo toxicity studies by implanting Si NMs on silk in the subdermal 
region of BALB/c mice, suggest this material is biocompatible, and that it has the potential to be used for long-term implantation [43]. Recently, in vitro cytotoxicity explored on 2D MoS films with L-929 cells and mouse fibroblast cells showed that there is no adverse effect on cell adherence and proliferation in vitro for 24 days. In vivo long-term cytotoxicity and biocompatibility studies with $\mathrm{MoS}_{2}$ layers implanting subcutaneously into BALB/c mice suggests that $\mathrm{MoS}_{2}$ does not cause any serious immunological or inflammatory reactions, and that it is, therefore, suitable for long-term biomedical use.
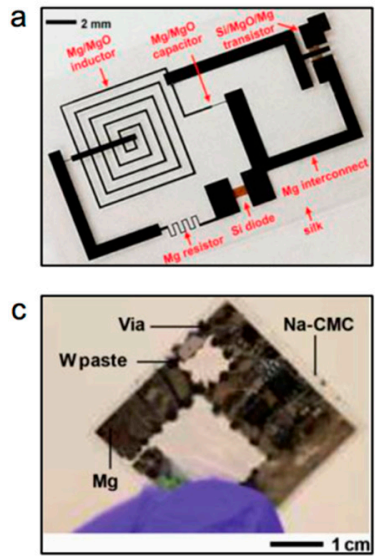
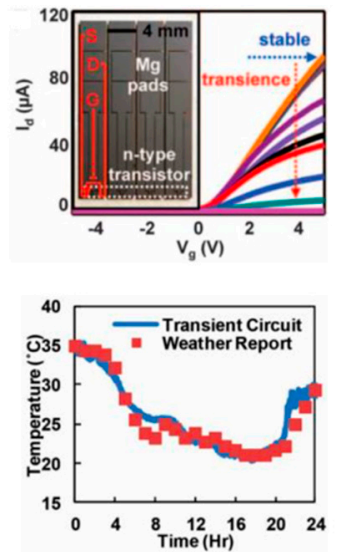
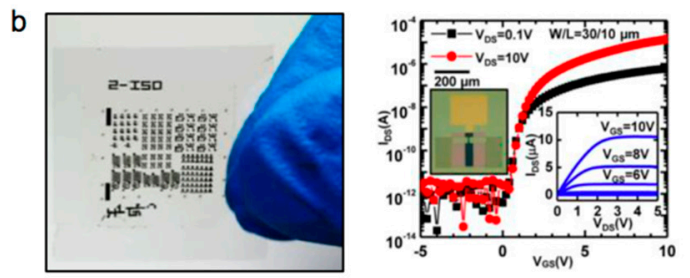

d

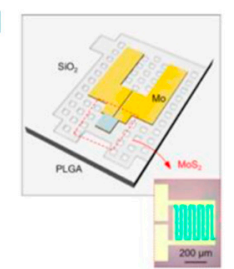

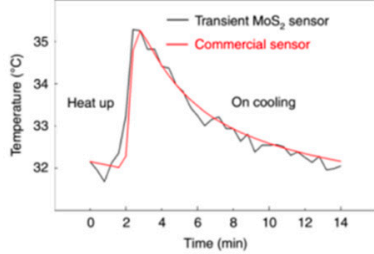

Figure 1. Different functional materials for soft and biodegradable devices. (a) Left: The circuit includes $\mathrm{Si} / \mathrm{MgO} / \mathrm{Mg}$ transistors, $\mathrm{Si}$ diodes, $\mathrm{Mg} / \mathrm{MgO}$ inductors, and capacitors, as well as $\mathrm{Mg}$ resistors and interconnectors. Right: The transience of the operational characteristics of n-channel transistors. (b) Left: Schematic illustrations of transient $\mathrm{Ga}_{2} \mathrm{O}_{3} / \mathrm{In}_{2} \mathrm{O}_{3} / \mathrm{ZnO}$ thin film transistors (TFTs) and circuits. Right: Transfer characteristics for $\mathrm{Ga}_{2} \mathrm{O}_{3} / \mathrm{In}_{2} \mathrm{O}_{3} / \mathrm{ZnO}$ TFTs with widths (W)/lengths (L) $(=30 / 10 \mu \mathrm{m})$. (c) Left: A transient printed circuit board (PCB) device with $\mathrm{W}$ and $\mathrm{Mg}$ for the temperature sensor; Right: Comparison for environmental temperatures measured by a transient circuit and the meteorological system. (d) Left: A multifunctional sensor using Mo and MoS $_{2}$; Right: Measurement of the intracranial temperature with transient $\mathrm{MoS}_{2}$ and commercial sensors. Reproduced with permission from $[14,27,28,45]$.

\subsection{Organic Functional Materials}

Conducting, semiconducting, and dielectric polymers are natural bridges between electronics and soft matter, because the vast chemical design space for polymers allows for the tunability of electronic, mechanical, and transient properties. A general strategy to create dielectric polymers is to incorporate high dielectric constant fills (e.g., $\mathrm{SiO}_{2}$, aluminum oxide $\left(\mathrm{Al}_{2} \mathrm{O}_{3}\right)$, hafnium oxide $\left(\mathrm{HfO}_{2}\right)$ ) into a polymer matrix [12]. To circumvent the use of inorganic fillers, plant-based fibers (e.g., cotton, jute, bamboo, and banana fibers), sugars (e.g., glucose and lactose), and DNA and its precursors are promising natural polymers that intrinsically possess practical dielectric properties [52-58].

For conducting polymers, conjugated polymers that have been doped into a conducting state are used for device interconnectors and contacts. Common conducting polymers are polypyrrole (PPy), polyanniline (PANI), and poly(3,4-ethylenedioxythiophene) (PEDOT) [59]. One strategy for fabricating biodegradable conducting polymers is to blend conjugated polymers with biodegradable, insulating polymers. It has to be noted that these composites fabricated in this way are partially degradable, which means they are disintegrable, but the conductive polymers parts cannot be fully broken down to their monomers. Fully biodegradable conductive polymers might be obtained by conjugation breaking, but the conductivity of the materials is relatively lower than the partially degradable conductive polymers [12]. In addition, typical semiconducting polymers are polythiophenes (e.g., poly(3-hexylthiophene), P3HT), and diketopyrrolopyrroles (DPP) [60,61]. 
As with conducting polymers, blending has been utilized to generate partially degradable semiconducting polymers, e.g., by blending poly(3-thiophene methyl acetate) (P3TMA), a derivative of P3HT, with thermoplastic polyurethane (TPU) [62]. Fully degradable polymeric semiconductors have been achieved recently by introducing reversible imine bonds between DPP and p-phenylenediamine [63]. Conjugated molecules found in nature could also be utilized to build biodegradable electronics, including the natural dye indigo from the plants Indigofera tinctorial and Isatis tinctorial [64], natural pigment melanins $[65,66]$, and $\beta$-carotene and anthraquinone derivatives $[54,67]$.

\subsection{Substrate Materials}

Compared with functional materials, often with thicknesses of a few hundreds of nanometers, substrate materials with thicknesses at the micrometer scale contribute to the majority of the weight. As for soft electronics, substrate materials are a critically important consideration, because their mechanical properties can dominate that of the integrated system. Polymeric materials are often used as flexible substrate materials. Candidate materials need to be compatible with device fabrication processes, which usually involves high temperatures, water, and harsh solvents and, therefore, considerations of material properties centering around thermal stability and solvent compatibility are necessary. Degradation times, swelling rates, mechanical robustness, and the biocompatibility of the substrate materials are also critical to guiding the selection of substrates and, thus, achieving devices with controlled operational timeframes, as well as characteristics that match tissue environments. Although the properties of polymeric substrates vary greatly from material to material, these substrates tend to be flexible and biodegradable.

Based on these requirements, a series of substrate polymeric materials have been explored, which can be classified into natural materials and synthesized polymers. Materials that already exist in the natural environment have been applied as the substrates for biomedical electronics. These materials are biologically derived, which possess affinities and hypo-allergenicities to the human body, such as silk fibroin, cellulose, and chitosan, etc. Silk fibroin protein shows attractive properties that are related to biotechnology and biomedical fields [68-72], and possesses proper mechanical strength, a tunable life time, and minimum immune rejection. The n-channel metal-oxide-semiconductor field-effect transistors (MOSFETs) have been deposited onto thin silk film successfully, as shown in Figure 2a [20]. With similar characteristics, cellulose and chitosan are two other natural substrate materials, as shown in Figures $2 b$ [63] and 2g [73], respectively. As a type of polysaccharide, cellulose is a richly-abundant substance in nature that composes of more than one-third of all plant components, and it even reaches an abundance of $90 \%$ in cotton [74]. Cellulose is a promising substrate for biomedical implants, as it takes advantage of attractive biocompatibility properties and degradation in a physiological environment [75-77]. Recently, a novel transistor system using $\mathrm{Al}_{2} \mathrm{O}_{3}$ as the dielectric layer and Fe as the electrodes, was prepared on ultrathin cellulose film to fabricate transient electronics [63]. In addition, as a derivative product of chitin by the deacetylation process, chitosan is another common substrate for temporary devices with proven biocompatibilities, as shown in Figure 2g [73]. Moreover, some other natural compounds such as potato starch, gelatin, or caramelized glucose have been used as substrates for designing biodegradable electronics [54]. Generally speaking, the dominant advantages of natural substrate materials are favorable, in terms of low-immunoreaction and great abundance, as well as low cost.

However, the intrinsic properties of natural materials limit their applications, as biodegradable electronics draw higher demands for substrates with specific properties relating to stability, mechanical strength, and degradation rate, etc., which promotes research for synthetic polymers [12]. Synthetic polymeric materials have been used in numerous biomedical applications for years, such as in bioresorbable stents and sutures [78-84]. Poly lactic-co-glycolic acid (PLGA) is a typical polymer that is used as a transient substrate, which is a copolymer of poly lactic acid (PLA) and poly glycolic acid (PGA). Compared to natural materials, the lifetime and mechanical strength of PLGA can be modified over a wide range by adjusting the ratio of PLA and PGA, which paves a 
promising path for biomedical implants with controllable working lives. In Figure $2 d$, transient complementary metal-oxide-semiconductors (CMOSs) are prepared on PLGA substrates with excellent operational characteristics [85]. Because of the different substrate requirements for biodegradable clinical devices, numerous polymers with different mechanical and disintegration performances are prepared and utilized as elastic substrate layers for soft and transient electronics, such as sodium carboxymethylcellulose (Na-CMC) [86], poly(caprolactone)-poly(glycerol sebacate)(PGS-PCL) [87], and poly(vinyl alcohol) (PVA) [27], etc., as shown in Figure 2c,e,f, respectively. Among them, PVA is a water-soluble polymer that forms flexible layers, which allows for the controlled transport rate of water through altering the crosslinking density of the chains and their subsequent swelling ratios. A recent report suggests that biodegradable elastomer poly (octamethylene maleate (anhydride) citrate) (POMaC) is an excellent candidate for applications in terms of its biocompatibility, mechanical properties, and degradation characteristics, which can be tuned by varying the polymerization conditions [88]. Besides, poly(1,8-octanediol-co-citrate) (POC) is a biodegradable elastomer that can take strains up to $\sim 30 \%$ with linear elastic mechanical responses. Hydrogels as hydrophilic polymeric networks with 3D microstructures represent alternative options that are highly biocompatible and suitable for biomimetic applications, due to their water-rich natures and structural similarities to natural extracellular matrices. Moreover, they can be designed to degrade under controlled modes and rates by enzymatic hydrolysis, ester hydrolysis, photolytic cleavage, or a combination of these reactions.

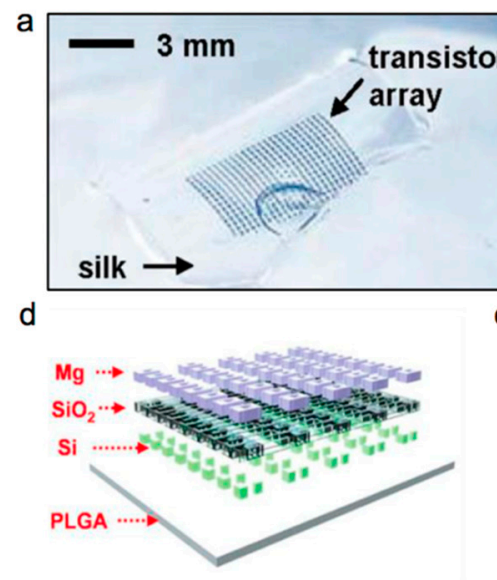

g

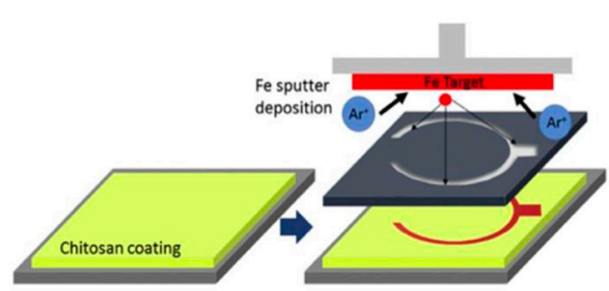

b

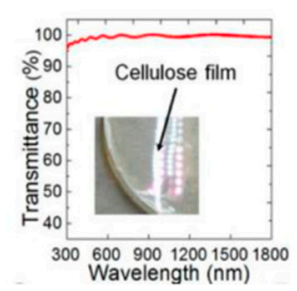

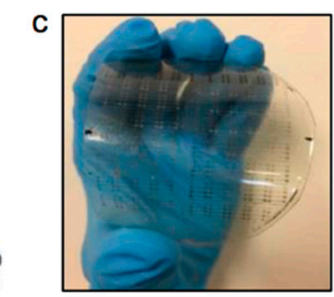
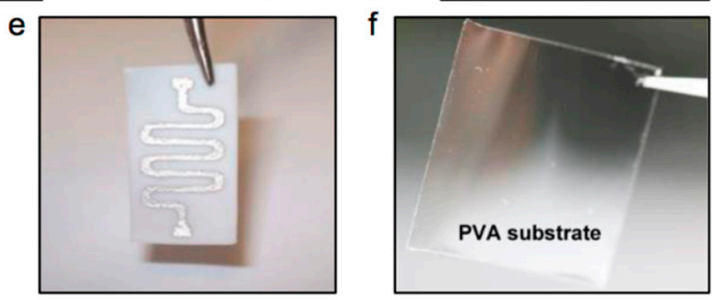

h Transistor array on Fe foil

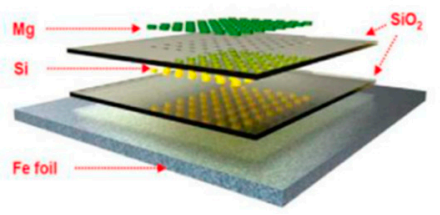

Figure 2. Various soft substrate materials for biodegradable electronics. (a) A silk substrate for transistor arrays. (b) A cellulose substrate for transistors. (c) A sodium carboxymethylcellulose (Na-CMC) bioresorbable substrate for Zn patterns. (d) A Poly lactic-co-glycolic acid (PLGA) substrate for transient electronic circuits. (e) An electrospun poly(caprolactone)-poly(glycerol sebacate) (PGS-PCL) sheet for a typical conductive pattern. (f) A PVA substrate for transient indium-gallium-zinc oxide (a-IGZO) TFTs. (g) A chitosan substrate for a biodegradable battery. (h) An Fe foil substrate for transistor arrays. Reproduced with permission from [20,27,47,63,85-87]. 
Although biodegradable polymeric substrates can often offer appropriate mechanical properties for soft and biodegradable electronics, direct device fabrication processed on polymer substrates is quite limited, as most types are sensitive to temperatures, solvents, or water. The swelling of most biodegradable polymers remains another challenge, as it can greatly shorten the functional lifetimes of electronic devices. Novel fabrication processes have been proposed to decouple polymeric substrates from the fabrication processes, which, however, introduce extra multiple fabrication steps; this will be discussed in the next section. Metal foils such as $\mathrm{Mo}, \mathrm{Fe}, \mathrm{W}$, and $\mathrm{Zn}$ have also been proposed as alternatives to polymeric biodegradable substrates, to offer better compatibility with the fabrication process, because they are relatively temperature-resistant, and because they address swelling issues upon deployment in aqueous solutions, as illustrated in Figure 2h [47]. They can also show excellent electrical and thermal properties, favorable water and oxygen isolation performances, and they are relatively resistant to most solvents. However, the rigid properties of metal foils might limit their further applications.

\subsection{Encapsulation Materials}

Encapsulation materials, together with substrate materials, define the lifetimes of biodegradable electronics. Similarly, most polymeric substrate materials can be used to form strain-tolerant encapsulation layers, preventing rapid degradation of devices, such as PLGA, PCL, etc. [21,89]. Silk fibroin pockets have also been demonstrated to be useful for the controlled modulation of the device lifetime [90]. Similarly, POC can be used not only as the substrate layer, but also as the encapsulation layer, for transient biomedical devices, to protect them from the environment. However, water permeation resistance within biodegradable polymeric materials often cannot satisfy the requirements of devices when a longer lifetime is needed, e.g., an encapsulated $\mathrm{Mg}$ trace with silk fibroin could lose its conductivity within a few hours [14]. Encapsulation using a Si membrane $(\sim 1.5 \mu \mathrm{m})$ has been explored, and it can significantly extend the degradation times of dissolvable metals, e.g., $\mathrm{Mg}$ thin films with $\mathrm{Si}$ encapsulation result in a lifetime of 60 days in phosphate-buffered saline at $37^{\circ} \mathrm{C}$ [44]. Bioresorbable electrocorticography electrodes based on $\mathrm{Si}$ encapsulation have demonstrated comparable recording results, compared to conventional standard electrodes, indicating the possibility of using a Si encapsulation layer for biodegradable electronics. In addition, alternating dielectric oxide layers of $\mathrm{SiO}_{2} / \mathrm{Si}_{3} \mathrm{~N}_{4} / \mathrm{SiO}_{2}$ has also been proven to possess good water permeation resistance [30]. Further studies are needed to investigate biodegradable encapsulation materials with ultralow water permeation rates, as well as appropriate electrical properties and mechanical flexibilities, to achieve a wider range of operational time frames. Strategies include combining inorganic/organic multilayer materials to improve flexibility, and to introduce smart stimuli-responsive materials to precisely control the starting point of degradation.

\section{Fabrication Schemes}

Traditional device fabrication often involves photolithography, deposition, and etching processes. For the biomedical application, it is important to note that the implanted bioresorbable electronics require soft properties to realize their conformal contact with organs and tissues. In addition to that, the manufacturing process should not introduce any toxic materials or solvents, to guarantee favorable biocompatibilities. Consequently, novel fabrication techniques are needed to ensure material compatibility with the processing parameters. 
For biodegradable devices, substrate materials with thicknesses at the micrometer scale contribute to the majority of the weight. Polymeric materials are often used as the substrates, because of their intrinsically soft and flexible properties, although metal foils have also been explored as an alternative [47]. Polymers are often dissolved into organic solvents and processed into a thin film format by drop casting, spin coating, or electrospinning methods. The thickness of the layer can be controlled by changing the relative solution concentrations, the speed of spin coating, or the electrospinning time $[87,91]$. The selections of proper solvents, spin-coating, or electrospinning parameters, and the surface treatments of handle substrates are critical to achieving free-standing polymer films with softness for the device fabrication.

The direct deposition of functional materials onto biodegradable and soft substrates, has been achieved through the use of shadow masks [14]. Decoupling fabrication processes from target biodegradable substrates through transfer-printing enables devices with a higher level of integration and more versatile material selections [85]. Figure 3a shows a transfer printing process utilizing foundry-based devices to achieve biodegradable 3D heterogeneous integrated circuits [21]. In order to obtain releasable micro-components from foundry-base wafers, a $\sim 700 \mathrm{~nm} \mathrm{SiN}$ passive layer is deposited by plasma-enhanced chemical-vapor deposition (PECVD), followed by inductively-coupled plasma-reactive ion etching (ICP-RIE) process to form trenches. Poly(dimethylsiloxane) (PDMS) stamps are then utilized in a transfer printing process to remove and deliver the target collections (a total thickness of $\sim 3 \mu \mathrm{m}$ ) onto target PLGA substrates. After that, a PLGA dielectric layer is prepared by the spin casting method, and a standard photolithography technology associated with RIE treatment, creates specific openings to make contact between the upper and lower layers. Another functional layer can then be prepared by applying a repeated procedure to finish the 3D integrated circuit. A combination of foundry-based $\mathrm{Si}$ wafers and transfer printing techniques provides a promising route towards high-performance and miniaturized biodegradable electronic systems.

\section{a}

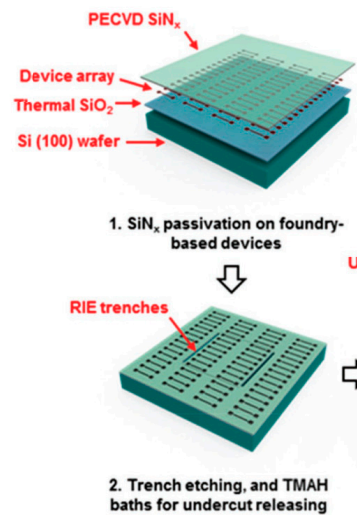

b
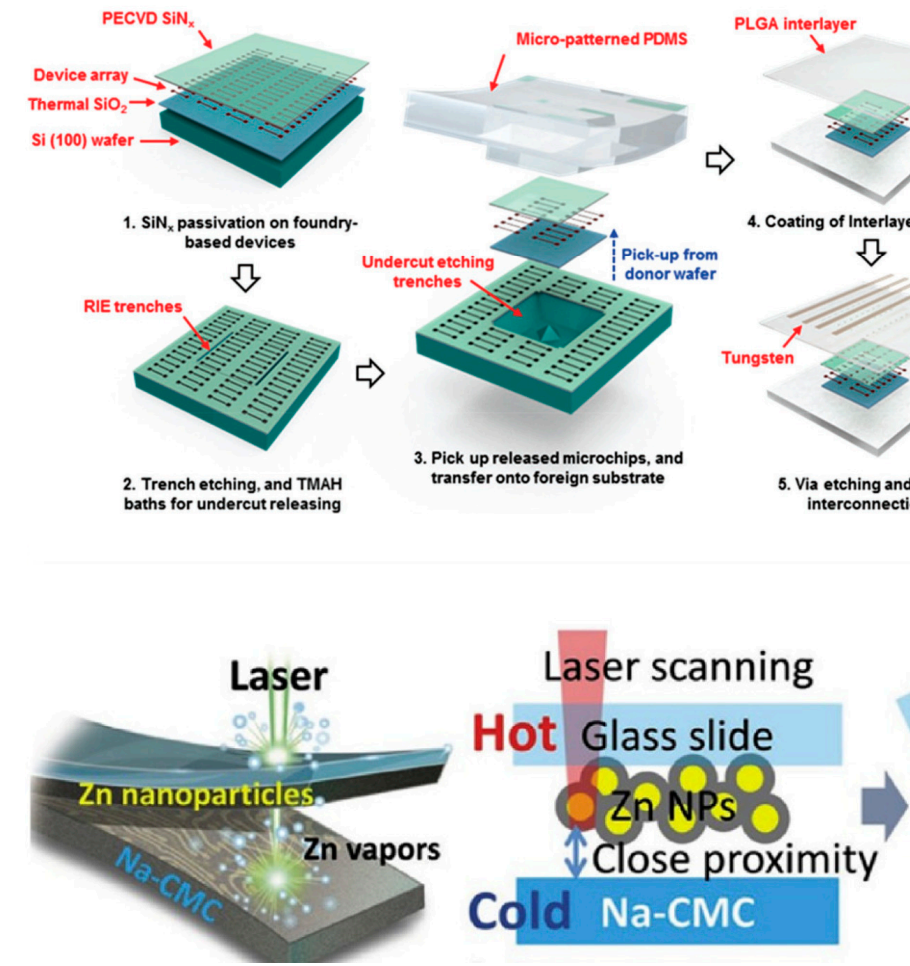

rema

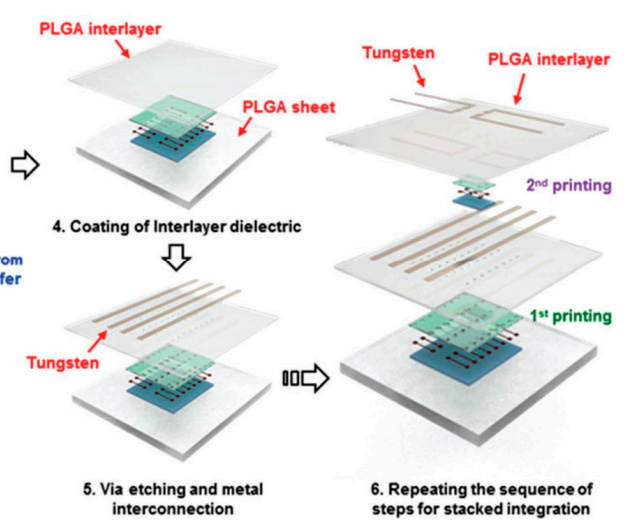

6. Repeating the sequence of
steps for stacked integration

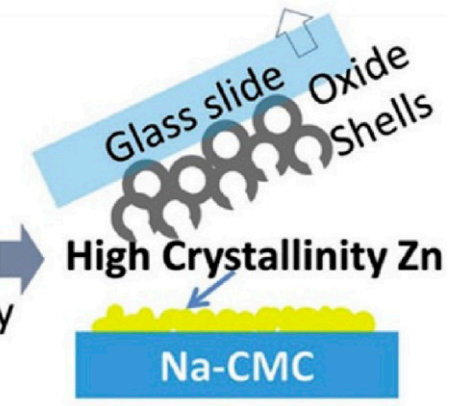

Figure 3. Fabrication schemes for soft and biodegradable electronics. (a) Preparation process of a 3D interconnected platform. Planarizing layers of PLGA serve as adhesives and interlayer dielectrics to facilitate 3D heterogeneous integration. (b) The schematic printing process for evaporation-condensation-mediated laser printing. Reproduced with permission from $[21,86]$. 
Printing techniques of biodegradable materials represent alternative methods to realize quick circuit patterns $[46,86,89,92]$. Figure $3 \mathrm{~b}$ illustrates a fabrication approach to manufacture bioresorbable electronics. A continuous-wave (CW) fiber laser is utilized to supply sintering power, so as to crystalize $\mathrm{Zn}$ nanoparticles onto a soft $\mathrm{Na}-\mathrm{CMC}$ substrate directly, with superior conductivity $\left(\sim 1.124 \times 10^{6} \mathrm{~S} \mathrm{~m}^{-1}\right)$ [86]. Such a fabrication technology offers a direct way for a roll-to-roll preparation platform to produce soft biodegradable electronics with high integration levels and low costs. In addition, highly conductive bioresorbable inks with an extended lifetime, consisting of polyanhydride and dispersed molybdenum microparticles, has also been reported. Such an ink can be applied to flexible wire and connection joints, as well as the antennas of bioresorbable devices [92]. These novel printing processes imply a fast and low-cost way to achieve biodegradable circuits.

\section{Representative Soft and Biodegradable Devices for Biomedical Applications}

Compared to conventional rigid implants, soft properties are favorable for biomedical implants to ensure conformally wrapping around biosystems that achieve intimate contact and minimize mechanical irritations, which are crucial and necessary for their applications, such as physiological signal detection and drug delivery. Combining biodegradable characteristics, devices can achieve fully bioresorption after usage, eliminating device retrieval. These devices could potentially serve as implantable diagnostic and therapeutic platforms, and they provide unprecedented physiological information and treatments, which are especially valuable for temporal biological processes, such as wound healing, neural network mapping, drug delivery, tissue regeneration, etc. Demonstrated soft and biodegradable electronic implants and pertinent power supply solutions will be reviewed in the following sections.

\subsection{Diagnostic Platforms}

For diagnostic purposes, because of their close connection with tissues and organs, soft transient electronics can detect abnormal physiological signals sensitively and precisely, even at the early stages of specific diseases, before they can be observed by conventional equipment, which is important for human healthcare and follow-up therapy. Figure 4 shows a soft and high-resolution recording system for electrocorticography (ECoG) based on Si devices [30], which offers a potential utility for treating neural disorders where biodegradation is required, to avoid tissue injury upon device removal. The flexible platform also enables the intimate contact of the device with the cerebral cortex, and allows for high-fidelity data recording. Figure 4 a illustrates the structure of the device, consisting of a flexible PLGA substrate $(\sim 30 \mu \mathrm{m})$, a Si nanomembrane semiconductor, a Mo electrode $(\sim 300 \mathrm{~nm}), \mathrm{a} \mathrm{SiO}_{2}$ gate dielectric, and $\mathrm{SiO}_{2}(\sim 300 \mathrm{~nm}) / \mathrm{Si}_{3} \mathrm{~N}_{4}(\sim 400 \mathrm{~nm}) / \mathrm{SiO}_{2}(\sim 300 \mathrm{~nm})$ interlayer dielectrics. The device includes 128 metal oxide-semiconductor field-effect transistors (MOSFETs). Figure $4 \mathrm{~b}$ exhibits the optical images of the unit cells of the device at different stages of fabrication, and a complete system. Figure $4 \mathrm{c}$ represents the linear (red) and log-scale (blue) transfer curves for representative n-channel MOSFET indication, with the mobility and on/off ratio of $\sim 400 \mathrm{~cm}^{2} \mathrm{~V}^{-1}$ and $\sim 10^{8}$, respectively. The device is implanted onto the whisker area, and Figure $4 \mathrm{~d}$ reveals the schematic illustration of the whisker stimulation locations in a rat model. By stimulating the defined positions, the related evoked potential in a spatial distribution is recorded, as given in Figure 4e, indicating high resolution mapping of ECoG that matches or exceeds any existing devices. The sensing system can completely dissolve into an aqueous buffer solution gradually at $\mathrm{pH}=12$ and at $37^{\circ} \mathrm{C}$, as shown in Figure $4 \mathrm{f}$. The sensitive sensing and biodegradable features of this transient device offer a promising application for internal physiological signal collection, which is significantly important for disease diagnosis. 
a
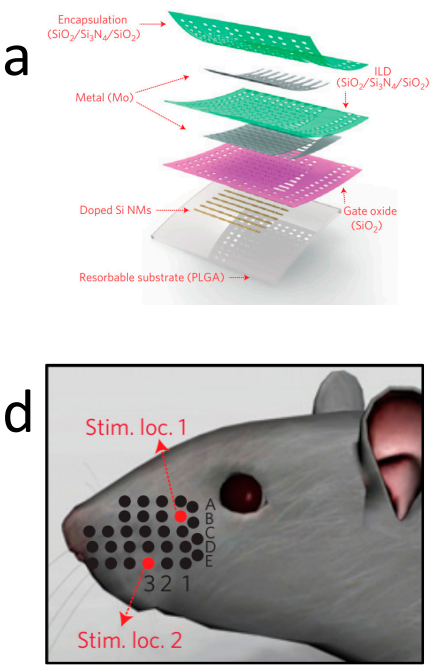

b
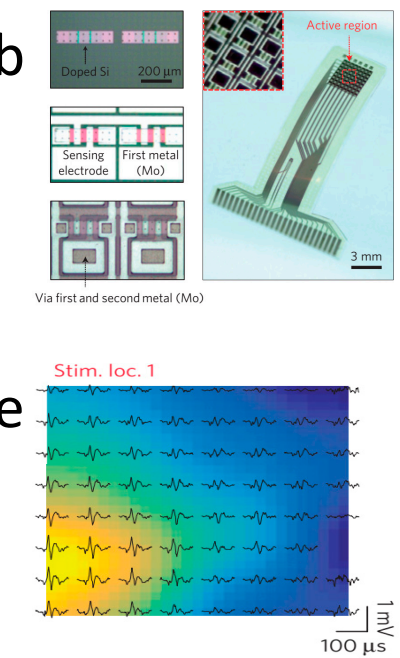

C
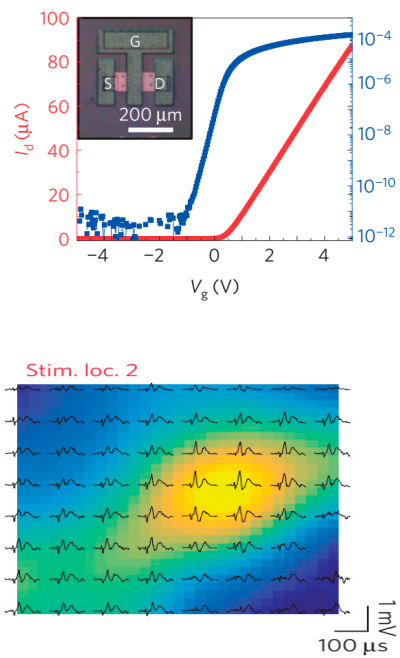

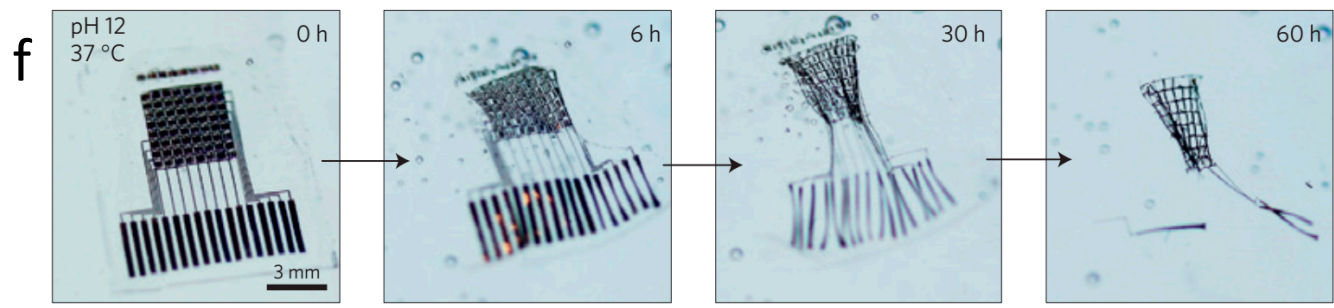

Figure 4. A soft and biodegradable neural electrode array sensor. (a) The schematic structure of an actively multiplexed sensing system for high-resolution electrocorticography. (b) Left: Optical micrograph images of a pair of subunits for the fabrication process. Right: The entire complete system. (c) Linear (red) and log scale (blue) transfer curves for a representative n-channel, MOSFET. (d) Schematic illustration of the whisker stimulation locations 1 and 2 (B1 and E3) in a rat model. (e) Left: Spatial distribution of the potentials evoked by the stimulation location B1. Right: Spatial distribution of the potentials evoked by stimulation location E3. (f) The degradation process at various stages of the sensor. Reproduced with permission from [30].

Stretchable and biodegradable pressure and strain sensors have also been reported for real-time monitoring for potential tendon recovery [88]. Figure 5a,b show the vertical structure and optical images of the sensor, respectively. The entire sensor is divided into four parts, including bottom and top encapsulation layers, as well as strain- and pressure-sensing areas, with $\mathrm{Mg}$ as the electrode, POMaC as the stretchable packaging layer, Poly(lactic acid) (PLLA) as the substrate, and PGS as the stretchable dielectric layer. Such a design allows for independent measurements of the strain and pressure. The sensor is implanted onto the back of a Sprague Dawley rat, as shown in Figure 5c. Figure 5d,e illustrate the collected pressure and strain signals after implantation for 2 and 3.5 weeks; the similar curves indicate a stable working performance. The biocompatibility of the sensor is demonstrated in Figure 5f, with CD68 positive cells decreasing gradually as the implantation period extends, suggesting that the inflammatory reaction is mitigated and, therefore, that excellent biocompatibility is reached. After more than two weeks of implantation, this sensor begins to degrade gradually. This research demonstrates the potential use of biodegradable devices for orthopedic applications. 


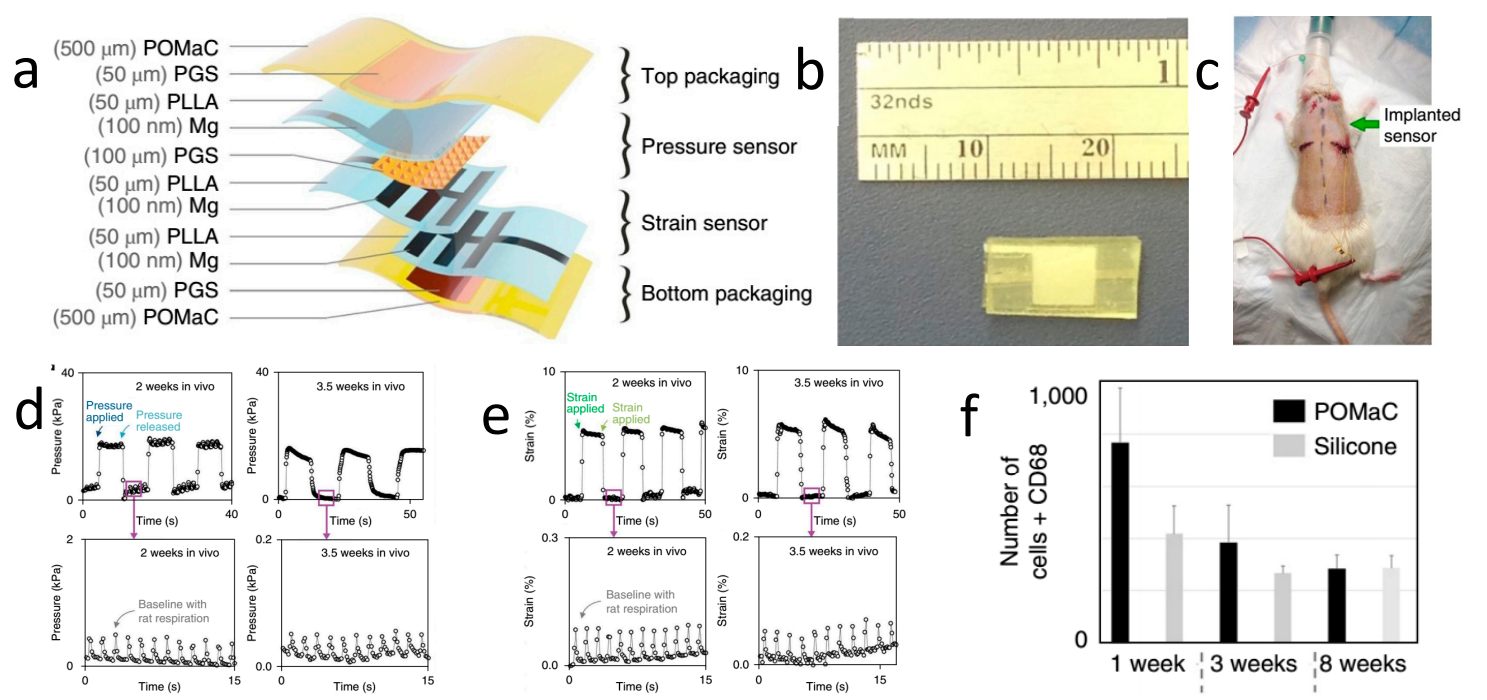

Figure 5. A stretchable and biodegradable strain and pressure sensor for orthopedic application. (a) Schematic diagram of the sensor space structure. (b) Optical image of the sensor. (c) The location of the implantable sensor. (d) Pressure signal detection two and 3.5 weeks after sensor implantation. (e) Strain signal detection two and 3.5 weeks after sensor implantation. (f) Results of immunohistochemistry. Reproduced with permission from [88].

\subsection{Therapeutic Devices}

In addition to diagnostic functions, soft and biodegradable electronics could also play an important role in therapeutic processes. For therapeutic platforms, flexible and biodegradable devices can offer personalized and precision treatments based on controlled performance and degradation rates. Bioresorbable devices can combine with drug delivery vehicles to achieve controlled drug release systems, which are critical for disease treatments.

The soft format of the sensor is favorable for controlled drug release with precise doses to specific areas, because of the conformal contact with tissues, which can improve treatment efficacy. Figure 6a displays the structure of a drug delivery system with a $2 \times 2$ array, consisting of inductive coupling coils and serpentine thermal heaters on a PLGA substrate [93]. The device allows for heating of the drug storage area through external wireless controls by inductive coupling. Drug release is thermally triggered by the phase transition of lipid layers imbedded with drugs. Figure $6 \mathrm{~b}$ (left) shows the total cumulative percentage of doxorubicin released as a function of time from a device that is immersed in deionized water $(12 \mathrm{~mL})$ when it is activated by wireless external power between 0.1 to $1.3 \mathrm{~W}$ at $12.5 \mathrm{MHz}$ and a distance of $2 \mathrm{~mm}$. The release rate of the drug can be adjusted by adjusting the supplied power. Figure $6 \mathrm{~b}$ (right) represents cumulative amounts of doxorubicin that are released wirelessly once a day, indicating good temperature-controlled drug release.

Wireless thermal therapy of bacterial management has also been demonstrated to assist with wound healing. Previous studies have revealed that some bacteria are highly sensitive to environmental changes, and that an increase in temperature lowers their survival [94-96]. Figure 6c (left) shows a transient radio frequency $(\mathrm{RF})$ device for thermal therapy based on the $\mathrm{Mg}$ heater, embedded between silk fibroin layers [97]. Figure $6 c$ (right) reveals related implantation processes for rats. The rats are infected by Staphylococcus aureus (S. aureus) with a subcutaneous injection $(\sim 5 \mu \mathrm{L})$ at the device implantation site, to mimic surgical site infections. The experimental rats are divided into untreated, low power $(100 \mathrm{~mW})$, and high power $(500 \mathrm{~mW})$ groups. Figure $6 \mathrm{~d}$ (left) shows a thermal image of a rat with a high power supply after 10 min heat treatments, with the temperature reaching $49^{\circ} \mathrm{C}$. The infected tissues were collected after $24 \mathrm{~h}$, and assessed by counting the normalized number of colony-forming units in the homogenates $(n=3)$ using standard plate-counting methods, and the related results are shown in Figure 6d (right). It is obvious that thermal treatment achieves a better 
bactericidal effect with higher temperatures. The concept of a biodegradable thermal therapy device can be widely applied to eliminate temperature-sensitive bacteria, which could be crucial to promoting the wound healing process.

a

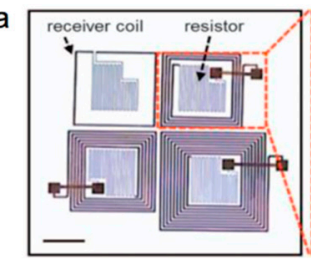

C

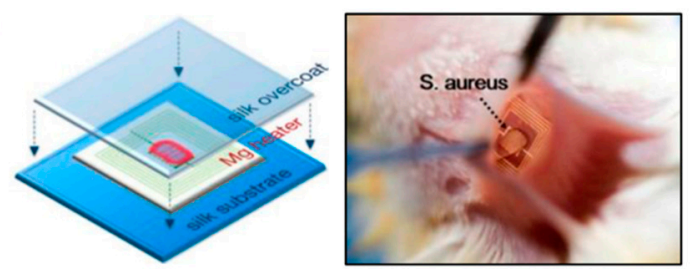

b
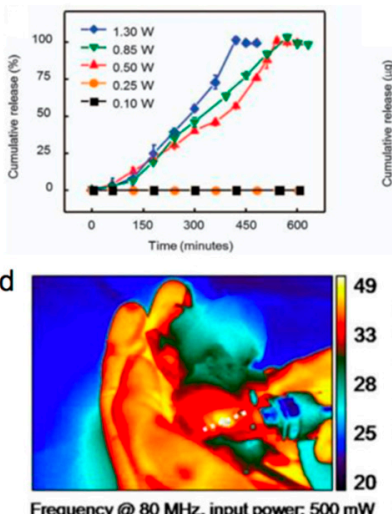
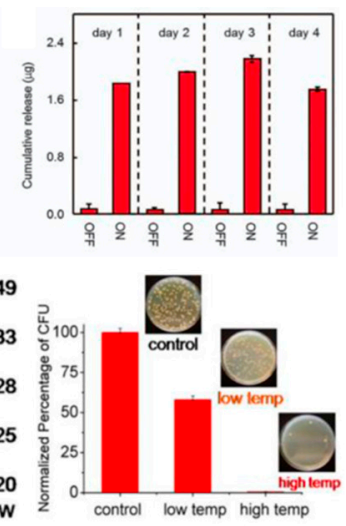

Figure 6. A thermally triggered drug delivery transient device and a radio frequency-controlled thermal therapy platform. (a) Images of the device structure. (b) Left: Cumulative release of doxorubicin from the device, operated with wireless power. Right: Controllable doxorubicin release from the device over 1 day on/off cycles. (c) Left: The schematic illustration of the radio frequency thermal therapy platform. Right: Photo of a device implanted in BALB/c mice. (d) Left: The thermal image of the device position while wirelessly powering the device. Right: The normalized number of colony-forming units after $24 \mathrm{~h}$ with different levels of input power. Reproduced with permission from [93,97].

\subsection{Power Supply}

Power supply is an essential component for biodegradable electronic systems, and great efforts have been made to explore biodegradable power sources, including batteries [98-102], supercapacitors [9], photovoltaic devices [103], radio frequency (RF) power scavengers [104], piezoelectric harvesters [25], etc. For biomedical applications, the power device should be flexible, stretchable, and miniaturized, to realize conformal contact and to minimize mechanical irritation.

A flexible and biodegradable RF wireless energy harvester appears in Figure 7a-d. Figure 7a,b illustrates the schematic structure of a wireless RF power transmitter, which consists of an RF antenna, an inductor, six capacitors, a resistor, and eight diodes [104]. By integrating with an Mg antenna, the RF system is capable of transmitting enough power to light up a red LED, as shown in Figure 7c. The entire system degrades rapidly in deionized water, as shown in Figure $7 \mathrm{~d}$. The demonstrated system provides a route for wireless energy harvesting for biodegradable implants; however, the current device volume limits its usage, and it needs further improvement. Figure 7e exhibits a flexible and biodegradable piezoelectric energy harvester based on $\mathrm{ZnO}$ on a silk substrate [25]. By bending the integrated film repeatedly, an output potential of $1.14 \mathrm{~V}$, and curves of $0.55 \mathrm{nA}$ are obtained, as shown in Figure $7 \mathrm{f}$. Figure $7 \mathrm{~g}$ illustrates the theoretical shape for the buckling of a device under compression. Although the piezoelectric energy harvester does not rely on an external device such as that for an RF energy scavenger, mechanical deformation inside the body is limited and, therefore, this limits the available power that can be obtained.

In summary, although various power solutions have been proposed, the performance of soft and biodegradable power supplies still remains an obstacle. The power density and the working life of the device should be further improved to satisfy the requirements of various biodegradable electronic systems. Materials and fabrication methods for power devices should also be advanced to achieve miniaturized, flexible, and stretchable platforms that are suitable as biomedical implants. 

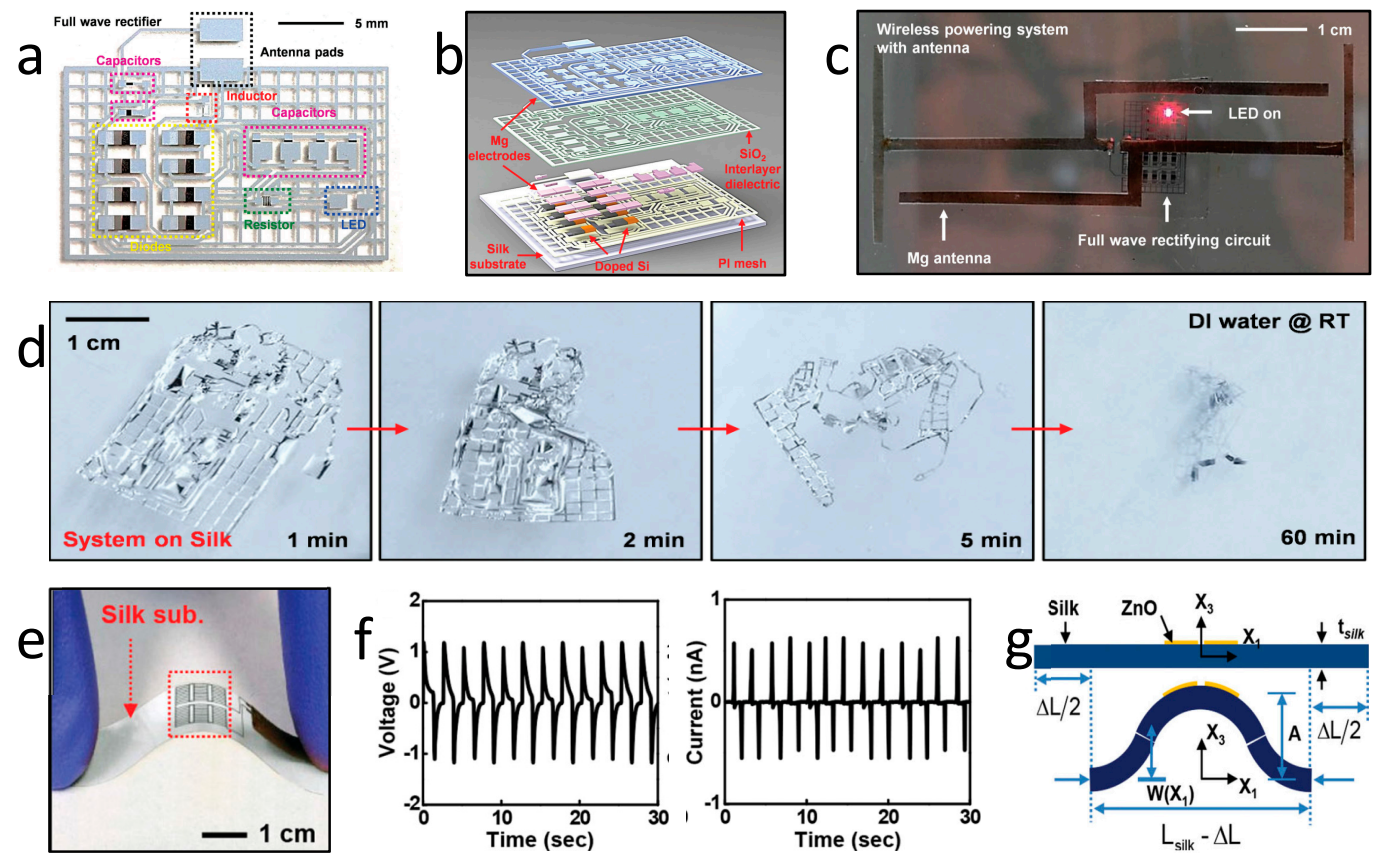

Figure 7. Flexible and biodegradable power harvesters. (a) A schematic illustration of transient RF power scavenging circuits. (b) A schematic illustration of an exploded view of the device. (c) An image of the device powered wirelessly with an RF transmitter and an Mg-receiving antenna. (d) Degradation process of the RF power harvester (e) Image of a soft and transient $\mathrm{ZnO}$ mechanical energy harvester on a silk substrate. (f) Output voltage and current ability during cycles of bending. (g) The theoretical shape for the buckling of a device under compression. Reproduced with permission from [25,104].

\section{Summary and Outlook}

As an emerging field, soft and biodegradable electronics have attracted more and more research interest because of their foreseeable applications for clinical implants, eco-friendly devices, and security hardware. For biodegradable biomedical devices, favorable biocompatibility, appropriate degradable rates, and robust mechanical properties, as well as superior performance, are desirable. Many studies have been made, to achieve remarkable progress towards biomedical applications.

However, there are still many issues that need to be addressed. More versatile materials with both biodegradable and soft properties need to be explored, to further broaden potential applications. For example, biodegradable functional materials that are highly stretchable and flexible could expand suitable implantation locations and significantly improve data recording sensitivities and accuracies, and minimize the irritation and inflammation that are associated with implantation. This could be achieved by developing composite structures that integrate hard and soft components, as well as through appropriate mechanical structure designs. Moreover, encapsulation materials with superior water resistance and soft properties are critical for waterproof sealing, to avoid the potential rupture of the encapsulation layer causing water leakage. Different from the fabrication methods for rigid biodegradable devices, novel fabrication technologies should be further explored to produce soft electronics with low costs and easy manufacturing procedures, as well as high levels of integration. In addition, the performance of soft devices, such as fast response and excellent sensitivity, as well as high accuracy, needs further improvement, and multifunctional electronics should be fabricated to meet the requirements of clinical standards. A comprehensive investigation of the device/tissue interface, and the metabolic processes of degradation products are also necessary to clarify the safety issues of biodegradable devices. These studies will improve the overall performance of soft and biodegradable devices, and they will promote the development of transient electronics, which could potentially make disease diagnosis and treatments more precise, effective, and intelligent. 
Author Contributions: Literature search, R.L. \& L.W.; Figures, R.L.; Tables, L.W.; Writing-Review \& Editing, R.L. \& L.W.; R.L. and L.W. contributed equally to the paper. Conceptualization \& Writing, L.Y.

Funding: This research was funded by [National Natural Science Foundation of China] grant number [51601103], [1000 Youth Talents Program in China], and [China Postdoctoral Science Foundation] grant number [2017M620769].

Acknowledgments: This work was supported by the National Natural Science Foundation of China (NSFC) 51601103 (L.Y.), 1000 Youth Talents Program in China (L.Y.), and the China Postdoctoral Science Foundation 2017M620769 (R.L.).

Conflicts of Interest: The authors declare no conflict of interest. The funders had no role in the design of the study; in the collection, analyses, or interpretation of data; in the writing of the manuscript, and in the decision to publish the results.

\section{References}

1. Dubal, D.P.; Chodankar, N.R.; Kim, D.H.; Gomez-Romero, P. Towards flexible solid-state supercapacitors for smart and wearable electronics. Chem. Soc. Rev. 2018, 47, 2065-2129. [CrossRef] [PubMed]

2. Annapureddy, V.; Na, S.M.; Hwang, G.T.; Kang, M.G.; Sriramdas, R.; Palneedi, H.; Yoon, W.H.; Hahn, B.D.; Kim, J.W.; Ahn, C.W.; et al. Exceeding milli-watt powering magneto-mechano-electric generator for standalone-powered electronics. Energy Environ. Sci. 2018, 11, 818-829. [CrossRef]

3. Salauddin, M.; Toyabur, R.M.; Maharjan, P.; Park, J.Y. High performance human-induced vibration driven hybrid energy harvester for powering portable electronics. Nano Energy 2018, 45, 236-246. [CrossRef]

4. Wang, S.H.; Xu, J.; Wang, W.C.; Wang, G.J.N.; Rastak, R.; Molina-Lopez, F.; Chung, J.W.; Niu, S.M.; Feig, V.R.; Lopez, J.; et al. Skin electronics from scalable fabrication of an intrinsically stretchable transistor array. Nature 2018, 555, 83-99. [CrossRef] [PubMed]

5. Falco, A.; Rivadeneyra, A.; Loghin, F.C.; Salmeron, J.F.; Lugli, P.; Abdelhalim, A. Towards low-power electronics: Self-recovering and flexible gas sensors. J. Mater. Chem. A 2018, 6, 7107-7113. [CrossRef]

6. Li, R.F.; Wang, L.; Kong, D.Y.; Yin, L. Recent progress on biodegradable materials and transient electronics. Bioact. Mater. 2018, 3, 322-333. [CrossRef] [PubMed]

7. Gao, Y.; Zhang, Y.; Wang, X.; Sim, K.; Liu, J.S.; Chen, J.; Feng, X.; Xu, H.X.; Yu, C.J. Moisture-triggered physically transient electronics. Sci. Adv. 2017, 3, e1701222. [CrossRef] [PubMed]

8. Yoon, J.; Lee, J.; Choi, B.; Lee, D.; Kim, D.H.; Kim, D.M.; Moon, D.I.; Lim, M.; Kim, S.; Choi, S.J. Flammable carbon nanotube transistors on a nitrocellulose paper substrate for transient electronics. Nano Res. 2017, 10, 87-96. [CrossRef]

9. Lee, G.; Kang, S.K.; Won, S.M.; Gutruf, P.; Jeong, Y.R.; Koo, J.; Lee, S.S.; Rogers, J.A.; Ha, J.S. Fully Biodegradable Microsupercapacitor for Power Storage in Transient Electronics. Adv. Energy Mater. 2017, 7, 1700157. [CrossRef]

10. Kang, S.-K.; Hwang, S.-W.; Cheng, H.; Yu, S.; Kim, B.H.; Kim, J.-H.; Huang, Y.; Rogers, J.A. Dissolution Behaviors and Applications of Silicon Oxides and Nitrides in Transient Electronics. Adv. Funct. Mater. 2014, 24, 4427-4434. [CrossRef]

11. Khanra, S.; Cipriano, T.; Lam, T.; White, T.A.; Fileti, E.E.; Alves, W.A.; Guha, S. Self-Assembled Peptide-Polyfluorene Nanocomposites for Biodegradable Organic Electronics. Adv. Mater. Interfaces 2015, 2 , 1500265. [CrossRef]

12. Feig, V.R.; Tran, H.; Bao, Z.N. Biodegradable Polymeric Materials in Degradable Electronic Devices. ACS Cent. Sci. 2018, 4, 337-348. [CrossRef] [PubMed]

13. Kang, S.K.; Koo, J.; Lee, Y.K.; Rogers, J.A. Advanced Materials and Devices for Bioresorbable Electronics. Acc. Chem. Res. 2018, 51, 988-998. [CrossRef] [PubMed]

14. Hwang, S.W.; Tao, H.; Kim, D.H.; Cheng, H.Y.; Song, J.K.; Rill, E.; Brenckle, M.A.; Panilaitis, B.; Won, S.M.; Kim, Y.S.; et al. A Physically Transient Form of Silicon Electronics. Science 2012, 337, 1640-1644. [CrossRef] [PubMed]

15. Kang, S.K.; Murphy, R.K.J.; Hwang, S.W.; Lee, S.M.; Harburg, D.V.; Krueger, N.A.; Shin, J.H.; Gamble, P.; Cheng, H.Y.; Yu, S.; et al. Bioresorbable silicon electronic sensors for the brain. Nature 2016, 530, 71. [CrossRef] [PubMed]

16. Irimia-Vladu, M.; Glowacki, E.D.; Voss, G.; Bauer, S.; Sariciftci, N.S. Green and biodegradable electronics. Mater. Today 2012, 15, 340-346. [CrossRef] 
17. Park, C.W.; Kang, S.K.; Hernandez, H.L.; Kaitz, J.A.; Wie, D.S.; Shin, J.; Lee, O.P.; Sottos, N.R.; Moore, J.S.; Rogers, J.A.; et al. Thermally Triggered Degradation of Transient Electronic Devices. Adv. Mater. 2015, 27, 3783-3788. [CrossRef] [PubMed]

18. Hernandez, H.L.; Kang, S.K.; Lee, O.P.; Hwang, S.W.; Kaitz, J.A.; Inci, B.; Park, C.W.; Chung, S.J.; Sottos, N.R.; Moore, J.S.; et al. Triggered Transience of Metastable Poly(phthalaldehyde) for Transient Electronics. Adv. Mater. 2014, 26, 7637-7642. [CrossRef] [PubMed]

19. Kim, D.H.; Lu, N.S.; Ma, R.; Kim, Y.S.; Kim, R.H.; Wang, S.D.; Wu, J.; Won, S.M.; Tao, H.; Islam, A.; et al. Epidermal Electronics. Science 2011, 333, 838-843. [CrossRef] [PubMed]

20. Hwang, S.W.; Kim, D.H.; Tao, H.; Kim, T.I.; Kim, S.; Yu, K.J.; Panilaitis, B.; Jeong, J.W.; Song, J.K.; Omenetto, F.G.; et al. Materials and Fabrication Processes for Transient and Bioresorbable High-Performance Electronics. Adv. Funct. Mater. 2013, 23, 4087-4093. [CrossRef]

21. Chang, J.K.; Chang, H.P.; Guo, Q.; Koo, J.; Wu, C.I.; Rogers, J.A. Biodegradable Electronic Systems in 3D, Heterogeneously Integrated Formats. Adv. Mater. 2018, 30, 1704955. [CrossRef] [PubMed]

22. Hwang, S.-W.; Park, G.; Edwards, C.; Corbin, E.A.; Kang, S.-K.; Cheng, H.; Song, J.-K.; Kim, J.-H.; Yu, S.; $\mathrm{Ng}$, J.; et al. Dissolution Chemistry and Biocompatibility of Single-Crystalline Silicon Nanomembranes and Associated Materials for Transient Electronics. ACS Nano 2014, 8, 5843-5851. [CrossRef] [PubMed]

23. Hwang, S.W.; Park, G.; Cheng, H.; Song, J.K.; Kang, S.K.; Yin, L.; Kim, J.H.; Omenetto, F.G.; Huang, Y.G.; Lee, K.M.; et al. 25th Anniversary Article: Materials for High-Performance Biodegradable Semiconductor Devices. Adv. Mater. 2014, 26, 1992-2000. [CrossRef] [PubMed]

24. Yin, L.; Farimani, A.B.; Min, K.; Vishal, N.; Lam, J.; Lee, Y.K.; Aluru, N.R.; Rogers, J.A. Mechanisms for hydrolysis of silicon nanomembranes as used in bioresorbable electronics. Adv. Mater. 2015, 27, 1857-1864. [CrossRef] [PubMed]

25. Dagdeviren, C.; Hwang, S.W.; Su, Y.W.; Kim, S.; Cheng, H.Y.; Gur, O.; Haney, R.; Omenetto, F.G.; Huang, Y.G.; Rogers, J.A. Transient, Biocompatible Electronics and Energy Harvesters Based on ZnO. Small 2013, 9, 3398-3404. [CrossRef] [PubMed]

26. Kang, S.K.; Park, G.; Kim, K.; Hwang, S.W.; Cheng, H.Y.; Shin, J.H.; Chung, S.J.; Kim, M.; Yin, L.; Lee, J.C.; et al. Dissolution Chemistry and Biocompatibility of Silicon- and Germanium-Based Semiconductors for Transient Electronics. ACS Appl. Mater. Interfaces 2015, 7, 9297-9305. [CrossRef] [PubMed]

27. Jin, S.H.; Kang, S.K.; Cho, I.T.; Han, S.Y.; Chung, H.U.; Lee, D.J.; Shin, J.; Baek, G.W.; Kim, T.I.; Lee, J.H.; et al. Water-Soluble Thin Film Transistors and Circuits Based on Amorphous Indium-Gallium-Zinc Oxide. ACS Appl. Mater. Interfaces 2015, 7, 8268-8274. [CrossRef] [PubMed]

28. Huang, X.; Liu, Y.H.; Hwang, S.W.; Kang, S.K.; Patnaik, D.; Cortes, J.F.; Rogers, J.A. Biodegradable Materials for Multilayer Transient Printed Circuit Boards. Adv. Mater. 2014, 26, 7371-7377. [CrossRef] [PubMed]

29. Yin, L.; Cheng, H.; Mao, S.; Haasch, R.; Liu, Y.; Xie, X.; Hwang, S.-W.; Jain, H.; Kang, S.-K.; Su, Y.; et al. Dissolvable Metals for Transient Electronics. Adv. Funct. Mater. 2014, 24, 645-658. [CrossRef]

30. Yu, K.J.; Kuzum, D.; Hwang, S.W.; Kim, B.H.; Juul, H.; Kim, N.H.; Won, S.M.; Chiang, K.; Trumpis, M.; Richardson, A.G.; et al. Bioresorbable silicon electronics for transient spatiotemporal mapping of electrical activity from the cerebral cortex. Nat. Mater. 2016, 15, 782. [CrossRef] [PubMed]

31. Institute of Medicine (US) Panel on Micronutrients. Dietary Reference Intakes for Vitamin A, Vitamin K, Arsenic, Boron, Chromium, Copper, Iodine, Iron, Manganese, Molybdenum, Nickel, Silicon, Vanadium, and Zinc; A Report of the Panel on Micronutrients, Subcommittees on Upper Reference Levels of Nutrients and of Interpretation and Uses of Dietary Reference Intakes, and the Standing Committee on the Scientific Evaluation of Dietary Reference Intakes; National Academy Press: Washington, DC, USA, 2001.

32. Ysart, G.; Miller, P.; Crews, H.; Robb, P.; Baxter, M.; De L'Argy, C.; Lofthouse, S.; Sargent, C.; Harrison, N. Dietary exposure estimates of 30 elements from the UK Total Diet Study. Food Addit. Contam. 1999, 16, 391-403. [CrossRef] [PubMed]

33. Millour, S.; Noel, L.; Chekri, R.; Vastel, C.; Kadar, A.; Sirot, V.; Leblanc, J.C.; Guerin, T. Strontium, silver, tin, iron, tellurium, gallium, germanium, barium and vanadium levels in foodstuffs from the Second French Total Diet Study. J. Food Compos. Anal. 2012, 25, 108-129. [CrossRef]

34. Tao, S.H.; Bolger, P.M. Hazard assessment of germanium supplements. Regul. Toxicol. Pharm. 1997, 25, 211-219. [CrossRef] [PubMed] 
35. James, B.; Zhang, W.L.; Sun, P.; Wu, M.Y.; Li, H.H.; Khaliq, M.A.; Jayasuriya, P.; James, S.; Wang, G. Tungsten (W) bioavailability in paddy rice soils and its accumulation in rice (Oryza sativa). Int. J. Environ. Health Res. 2017, 27, 487-497. [CrossRef] [PubMed]

36. Institute of Medicine (US) Standing Committee on the Scientific Evaluation of Dietary Reference Intakes. Dietary Reference Intakes for Calcium, Phosphorus, Magnesium, Vitamin D, and Fluoride; National Academy Press: Washington, DC, USA, 1997.

37. Rogers, J.A.; Lagally, M.G.; Nuzzo, R.G. Synthesis, assembly and applications of semiconductor nanomembranes. Nature 2011, 477, 45-53. [CrossRef] [PubMed]

38. Hofmann, S.; Ducati, C.; Neill, R.J.; Piscanec, S.; Ferrari, A.C.; Geng, J.; Dunin-Borkowski, R.E.; Robertson, J. Gold catalyzed growth of silicon nanowires by plasma enhanced chemical vapor deposition. J. Appl. Phys. 2003, 94, 6005-6012. [CrossRef]

39. Guo, X.L.; Tabata, H.; Kawai, T. Pulsed laser reactive deposition of p-type ZnO film enhanced by an electron cyclotron resonance source. J. Cryst. Growth 2001, 223, 135-139. [CrossRef]

40. Schropp, R.E.I.; Feenstra, K.E.; Molenbroek, E.C.; Meiling, H.; Rath, J.K. Device-quality polycrystalline and amorphous silicon films by hot-wire chemical vapour deposition. Philos. Mag. B 1997, 76, 309-321. [CrossRef]

41. Lee, W.J.; Park, W.T.; Park, S.; Sung, S.; Noh, Y.Y.; Yoon, M.H. Large-Scale Precise Printing of Ultrathin Sol-Gel Oxide Dielectrics for Directly Patterned Solution-Processed Metal Oxide Transistor Arrays. Adv. Mater. 2015, 27, 5043-5048. [CrossRef] [PubMed]

42. Kim, D.H.; Ghaffari, R.; Lu, N.S.; Rogers, J.A. Flexible and Stretchable Electronics for Biointegrated Devices. Annu. Rev. Biomed. Eng. 2012, 14, 113-128. [CrossRef] [PubMed]

43. Ahn, J.H.; Kim, H.S.; Lee, K.J.; Jeon, S.; Kang, S.J.; Sun, Y.G.; Nuzzo, R.G.; Rogers, J.A. Heterogeneous three-dimensional electronics by use of printed semiconductor nanomaterials. Science 2006, 314, 1754-1757. [CrossRef] [PubMed]

44. Lee, Y.K.; Yu, K.J.; Song, E.M.; Farimani, A.B.; Vitale, F.; Xie, Z.Q.; Yoon, Y.; Kim, Y.; Richardson, A.; Luan, H.W.; et al. Dissolution of Monocrystalline Silicon Nanomembranes and Their Use as Encapsulation Layers and Electrical Interfaces in Water-Soluble Electronics. ACS Nano 2017, 11, 12562-12572. [CrossRef] [PubMed]

45. Chen, X.; Park, Y.J.; Kang, M.; Kang, S.K.; Koo, J.; Shinde, S.M.; Shin, J.; Jeon, S.; Park, G.; Yan, Y.; et al. CVD-grown monolayer MoS2 in bioabsorbable electronics and biosensors. Nat. Commun. 2018, 9, 1690. [CrossRef] [PubMed]

46. Mahajan, B.K.; Yu, X.W.; Shou, W.; Pan, H.; Huang, X. Mechanically Milled Irregular Zinc Nanoparticles for Printable Bioresorbable Electronics. Small 2017, 13, 1700065. [CrossRef] [PubMed]

47. Kang, S.-K.; Hwang, S.-W.; Yu, S.; Seo, J.-H.; Corbin, E.A.; Shin, J.; Wie, D.S.; Bashir, R.; Ma, Z.; Rogers, J.A. Biodegradable Thin Metal Foils and Spin-On Glass Materials for Transient Electronics. Adv. Funct. Mater. 2015, 25, 1789-1797. [CrossRef]

48. Kirkland, N.T.; Birbilis, N.; Staiger, M.P. Assessing the corrosion of biodegradable magnesium implants: A critical review of current methodologies and their limitations. Acta Biomater. 2012, 8, 925-936. [CrossRef] [PubMed]

49. Bowen, P.K.; Drelich, J.; Goldman, J. Zinc Exhibits Ideal Physiological Corrosion Behavior for Bioabsorbable Stents. Adv. Mater. 2013, 25, 2577-2582. [CrossRef] [PubMed]

50. Badawy, W.A.; Al-Kharafi, F.M. Corrosion and passivation behaviors of molybdenum in aqueous solutions of different pH. Electrochim. Acta 1998, 44, 693-702. [CrossRef]

51. Patrick, E.; Orazem, M.E.; Sanchez, J.C.; Nishida, T. Corrosion of tungsten microelectrodes used in neural recording applications. J. Neurosci. Meth. 2011, 198, 158-171. [CrossRef] [PubMed]

52. Hemstreet, J.M. Dielectric constant of cotton. J. Electrost. 1982, 13, 345-353. [CrossRef]

53. Jayamani, E.; Hamdan, S.; Rahman, M.R.; Bin Bakri, M.K. Comparative Study of Dielectric Properties of Hybrid Natural Fiber Composites. Procedia Eng. 2014, 97, 536-544. [CrossRef]

54. Irimia-Vladu, M.; Troshin, P.A.; Reisinger, M.; Shmygleva, L.; Kanbur, Y.; Schwabegger, G.; Bodea, M.; Schwodiauer, R.; Mumyatov, A.; Fergus, J.W.; et al. Biocompatible and Biodegradable Materials for Organic Field-Effect Transistors. Adv. Funct. Mater. 2010, 20, 4069-4076. [CrossRef]

55. Singh, T.B.; Sariciftci, N.S.; Grote, J.G. Bio-Organic Optoelectronic Devices Using DNA. Org. Electron. 2010, 223, 189-212. 
56. Yumusak, C.; Singh, T.B.; Sariciftci, N.S.; Grote, J.G. Bioorganic field effect transistors based on crosslinked deoxyribonucleic acid (DNA) gate dielectric. Appl. Phys. Lett. 2009, 95, 263304. [CrossRef]

57. Singh, B.; Sariciftci, N.S.; Grote, J.G.; Hopkins, F.K. Bioorganic-semiconductor-field-effect-transistor based on deoxyribonucleic acid gate dielectric. J. Appl. Phys. 2006, 100, 024514. [CrossRef]

58. Wang, L.; Yoshida, J.; Ogata, N.; Sasaki, S.; Kajiyama, T. Self-Assembled Supramolecular Films Derived from Marine Deoxyribonucleic Acid (DNA)-Cationic Surfactant Complexes: Large-Scale Preparation and Optical and Thermal Properties. Chem. Mater. 2001, 13, 1273-1281. [CrossRef]

59. Worfolk, B.J.; Andrews, S.C.; Park, S.; Reinspach, J.; Liu, N.; Toney, M.F.; Mannsfeld, S.C.; Bao, Z.N. Ultrahigh electrical conductivity in solutionsheared polymeric transparent films. Proc. Natl. Acad. Sci. USA 2015, 112, 14138-14143. [CrossRef] [PubMed]

60. Qiao, Y.L.; Guo, Y.L.; Yu, C.M.; Zhang, F.J.; Xu, W.; Liu, Y.Q.; Zhu, D.B. Diketopyrrolopyrrole-Containing Quinoidal Small Molecules for High-Performance, Air-Stable, and Solution-Processable n-Channel Organic Field-Effect Transistors. J. Am. Chem. Soc. 2012, 134, 4084-4087. [CrossRef] [PubMed]

61. Chen, H.J.; Guo, Y.L.; Yu, G.; Zhao, Y.; Zhang, J.; Gao, D.; Liu, H.T.; Liu, Y.Q. Highly p-Extended Copolymers with Diketopyrrolopyrrole Moieties for High-Performance Field-Effect Transistors. Adv. Mater. 2012, 24, 4618-4622. [CrossRef] [PubMed]

62. Madrigal, M.M.P.; Giannotti, M.I.; Oncins, G.; Franco, L.; Armelin, E.; Puiggali, J.; Sanz, F.; del Valle, L.J.; Aleman, C. Bioactive nanomembranes of semiconductor polythiophene and thermoplastic polyurethane: Thermal, nanostructural and nanomechanical properties. Polym. Chem. 2013, 4, 568-583. [CrossRef]

63. Lei, T.; Guan, M.; Liu, J.; Lin, H.C.; Pfattner, R.; Shaw, L.; McGuire, A.F.; Huang, T.C.; Shao, L.L.; Cheng, K.T.; et al. Biocompatible and totally disintegrable semiconducting polymer for ultrathin and ultralightweight transient electronics. Proc. Natl. Acad. Sci. USA 2017, 114, 5107-5112. [CrossRef] [PubMed]

64. Irimia-Vladu, M.; Glowacki, E.D.; Troshin, P.A.; Schwabegger, G.; Leonat, L.; Susarova, D.K.; Krystal, O.; Ullah, M.; Kanbur, Y.; Bodea, M.A.; et al. Indigo-A Natural Pigment for High Performance Ambipolar Organic Field Effect Transistors and Circuits. Adv. Mater. 2012, 24, 375-380. [CrossRef] [PubMed]

65. Mostert, A.B.; Powell, B.J.; Pratt, F.L.; Hanson, G.R.; Sarna, T.; Gentle, I.R.; Meredith, P. Role of semiconductivity and ion transport in the electrical conduction of melanin. Proc. Natl. Acad. Sci. USA 2012, 109, 8943-8947. [CrossRef] [PubMed]

66. Bettinger, C.J.; Bruggeman, P.P.; Misra, A.; Borenstein, J.T.; Langer, R. Biocompatibility of biodegradable semiconducting melanin films for nerve tissue engineering. Biomaterials 2009, 30, 3050-3057. [CrossRef] [PubMed]

67. Ramachandran, G.K.; Tomfohr, J.K.; Li, J.; Sankey, O.F.; Zarate, X.; Primak, A.; Terazono, Y.; Moore, T.A.; Moore, A.L.; Gust, D.; et al. Electron transport properties of a carotene molecule in a metal-(single molecule)-metal junction. J. Phys. Chem. B 2003, 107, 6162-6169. [CrossRef]

68. Koh, L.D.; Yeo, J.; Lee, Y.Y.; Ong, Q.; Han, M.Y.; Tee, B.C.K. Advancing the frontiers of silk fibroin protein-based materials for futuristic electronics and clinical wound-healing. Mater. Sci. Eng. C Mater. 2018, 86, 151-172. [CrossRef] [PubMed]

69. Li, G.; Li, Y.; Chen, G.Q.; He, J.H.; Han, Y.F.; Wang, X.Q.; Kaplan, D.L. Silk-Based Biomaterials in Biomedical Textiles and Fiber-Based Implants. Adv. Healthc. Mater. 2015, 4, 1134-1151. [CrossRef] [PubMed]

70. Xie, M.B.; Li, Y.; Li, J.S.; Chen, A.Z.; Zhao, Z.; Li, G. Biomedical Applications of Silk Fibroin. In Textile Bioengineering and Informatics Symposium Proceedings; Textile Bioengineering \& Informatics Society Ltd.: Hong Kong, China, 2014; Volumes 1 and 2, pp. 207-218.

71. Taddei, P.; Chiono, V.; Anghileri, A.; Vozzi, G.; Freddi, G.; Ciardelli, G. Silk Fibroin/Gelatin Blend Films Crosslinked with Enzymes for Biomedical Applications. Macromol. Biosci. 2013, 13, 1492-1510. [CrossRef] [PubMed]

72. Pal, R.K.; Farghaly, A.A.; Wang, C.Z.; Collinson, M.M.; Kundu, S.C.; Yadavalli, V.K. Conducting polymer-silk biocomposites for flexible and biodegradable electrochemical sensors. Biosens. Bioelectron. 2016, 81, $294-302$. [CrossRef] [PubMed]

73. Edupuganti, V.; Solanki, R. Fabrication, characterization, and modeling of a biodegradable battery for transient electronics. J. Power Sources 2016, 336, 447-454. [CrossRef]

74. Jiang, L.; Zhang, J. Biodegradable and biobased polymers. In Applied Plastics Engineering Handbook, 2nd ed.; William Andrew Publishing: Oxford, UK, 2017; pp. 127-143. 
75. Zhu, H.L.; Fang, Z.Q.; Preston, C.; Li, Y.Y.; Hu, L.B. Transparent paper: Fabrications, properties, and device applications. Energy Environ. Sci. 2014, 7, 269-287. [CrossRef]

76. Zhu, H.L.; Xiao, Z.G.; Liu, D.T.; Li, Y.Y.; Weadock, N.J.; Fang, Z.Q.; Huang, J.S.; Hu, L.B. Biodegradable transparent substrates for flexible organic-light-emitting diodes. Energy Environ. Sci. 2013, 6, 2105-2111. [CrossRef]

77. Jung, Y.H.; Chang, T.H.; Zhang, H.L.; Yao, C.H.; Zheng, Q.F.; Yang, V.W.; Mi, H.Y.; Kim, M.; Cho, S.J.; Park, D.W.; et al. High-performance green flexible electronics based on biodegradable cellulose nanofibril paper. Nat. Commun. 2015, 6, 7170. [CrossRef] [PubMed]

78. Li, Z.Q.; Wang, H.C.; Lv, S.Z.; Liu, L.; Guo, W.Y.; Yuan, M.; Yan, H.B.; Zhao, H.J.; Lang, S.P. Clinical Comparative Study on Efficacy and Safety for Treatment of Coronary Heart Disease with Cobalt-Base Alloy Bio Absorbable Polymer Sirolimus-Eluting Stent and Partner Stent. Heart 2011, 97, A149. [CrossRef]

79. Wu, Y.T.; Gao, Y.C. Five Years Follow Up Result after Application of Biodegradable Polymer Sirolimus-Eluting Stent in Patients with Coronary Heart Disease and Diabetes Mellitus. Heart 2013, 99, E175.

80. Inigo-Garcia, L.A.; Martinez-Garcia, F.J.; Milan-Pinilla, A.; Valle-Alberca, A.; Fernandez-Lopez, L.; Traverso-Castilla, V.V.; Delgado-Aguilar, A.; Bravo-Marques, R.; Ramirez-Moreno, A.; Siles-Rubio, J.R. Biodegradable Polymer Drug Eluting Stent: Efficacy and Safety with Short Regimen of Antiplatelet Therapy. Cardiology 2016, 134, 48.

81. Pilgrim, T.; Heg, D.; Roffi, M.; Tuller, D.; Muller, O.; Vuilliomenet, A.; Cook, S.; Weilenmann, D.; Kaiser, C.; Jamshidi, P.; et al. Ultrathin strut biodegradable polymer sirolimus-eluting stent versus durable polymer everolimus-eluting stent for percutaneous coronary revascularisation (BIOSCIENCE): A randomised, single-blind, non-inferiority trial. Lancet 2014, 384, 2111-2122. [CrossRef]

82. Waksman, R.; Pakala, R.; Baffour, R.; Seabron, R.; Hellinga, D.; Chan, R.; Su, S.H.; Kolodgie, F.; Virmani, R. In vivo comparison of a polymer-free Biolimus A9-eluting stent with a biodegradable polymer-based Biolimus A9 eluting stent and a bare metal stent in balloon denuded and radiated hypercholesterolemic rabbit iliac arteries. Catheter. Cardiovasc. Interv. 2012, 80, 429-436. [CrossRef] [PubMed]

83. Balch, O.K.; Collier, M.A.; DeBault, L.E.; Johnson, L.L. Bioabsorbable suture anchor (co-polymer 85/15 D,L lactide/glycolide) implanted in bone: Correlation of physical/mechanical properties, magnetic resonance imaging, and histological response. Arthroscopy 1999, 15, 691-708. [CrossRef]

84. Im, S.H.; Jung, Y.; Kim, S.H. Current status and future direction of biodegradable metallic and polymeric vascular scaffolds for next-generation stents. Acta Biomater. 2017, 60, 3-22. [CrossRef] [PubMed]

85. Hwang, S.W.; Song, J.K.; Huang, X.; Cheng, H.Y.; Kang, S.K.; Kim, B.H.; Kim, J.H.; Yu, S.; Huang, Y.G.; Rogers, J.A. High-Performance Biodegradable/Transient Electronics on Biodegradable Polymers. Adv. Mater. 2014, 26, 3905-3911. [CrossRef] [PubMed]

86. Shou, W.; Mahajan, B.K.; Ludwig, B.; Yu, X.W.; Staggs, J.; Huang, X.; Pan, H. Low-Cost Manufacturing of Bioresorbable Conductors by Evaporation-Condensation-Mediated Laser Printing and Sintering of $\mathrm{Zn}$ Nanoparticles. Adv. Mater. 2017, 29, 1700172. [CrossRef] [PubMed]

87. Najafabadi, A.H.; Tamayol, A.; Annabi, N.; Ochoa, M.; Mostafalu, P.; Akbari, M.; Nikkhah, M.; Rahimi, R.; Dokmeci, M.R.; Sonkusale, S.; et al. Biodegradable Nanofibrous Polymeric Substrates for Generating Elastic and Flexible Electronics. Adv. Mater. 2014, 26, 5823-5830. [CrossRef] [PubMed]

88. Boutry, C.M.; Kaizawa, Y.; Schroeder, B.C.; Chortos, A.; Legrand, A.; Wang, Z.; Chang, J.; Fox, P.; Bao, Z. A stretchable and biodegradable strain and pressure sensor for orthopaedic application. Nat. Electron. 2018, 1, 314-321. [CrossRef]

89. Lee, Y.K.; Kim, J.; Kim, Y.; Kwak, J.W.; Yoon, Y.; Rogers, J.A. Room Temperature Electrochemical Sintering of Zn Microparticles and Its Use in Printable Conducting Inks for Bioresorbable Electronics. Adv. Mater. 2017, 29, 1702665. [CrossRef] [PubMed]

90. Brenckle, M.A.; Cheng, H.Y.; Hwang, S.; Tao, H.; Paquette, M.; Kaplan, D.L.; Rogers, J.A.; Huang, Y.G.; Omenetto, F.G. Modulated Degradation of Transient Electronic Devices through Multilayer Silk Fibroin Pockets. ACS Appl. Mater. Interfaces 2015, 7, 19870-19875. [CrossRef] [PubMed]

91. Pan, R.Z.; Xuan, W.P.; Chen, J.K.; Dong, S.R.; Jin, H.; Wang, X.Z.; Li, H.L.; Luo, J.K. Fully biodegradable triboelectric nanogenerators based on electrospun polylactic acid and nanostructured gelatin films. Nano Energy 2018, 45, 193-202. [CrossRef] 
92. Lee, S.; Koo, J.; Kang, S.K.; Park, G.; Lee, Y.J.; Chen, Y.Y.; Lim, S.A.; Lee, K.M.; Rogers, J.A. Metal microparticle-Polymer composites as printable, bio/ecoresorbable conductive inks. Mater. Today 2018, 21, 207-215. [CrossRef]

93. Lee, C.H.; Kim, H.; Harburg, D.V.; Park, G.; Ma, Y.J.; Pan, T.S.; Kim, J.S.; Lee, N.Y.; Kim, B.H.; Jang, K.I.; et al. Biological lipid membranes for on-demand, wireless drug delivery from thin, bioresorbable electronic implants. Npg Asia Mater. 2015, 7, e227. [CrossRef] [PubMed]

94. White, M.D.; Bosio, C.M.; Duplantis, B.N.; Nano, F.E. Human body temperature and new approaches to constructing temperature-sensitive bacterial vaccines. Cell. Mol. Life Sci. 2011, 68, 3019-3031. [CrossRef] [PubMed]

95. Duplantis, B.N.; Bosio, C.M.; Nano, F.E. Temperature-sensitive bacterial pathogens generated by the substitution of essential genes from cold-loving bacteria: Potential use as live vaccines. J. Mol. Med. 2011, 89, 437-444. [CrossRef] [PubMed]

96. Hooke, A.M. Temperature-Sensitive Mutants of Bacterial Pathogens-Isolation and Use to Determine Host Clearance and In-Vivo Replication Rates. Method Enzymol. 1994, 235, 448-457.

97. Tao, H.; Hwang, S.W.; Marelli, B.; An, B.; Moreau, J.E.; Yang, M.M.; Brenckle, M.A.; Kim, S.; Kaplan, D.L.; Rogers, J.A.; et al. Silk-based resorbable electronic devices for remotely controlled therapy and in vivo infection abatement. Proc. Natl. Acad. Sci. USA 2014, 111, 17385-17389. [CrossRef] [PubMed]

98. Yin, L.; Huang, X.; Xu, H.X.; Zhang, Y.F.; Lam, J.; Cheng, J.J.; Rogers, J.A. Materials, Designs, and Operational Characteristics for Fully Biodegradable Primary Batteries. Adv. Mater. 2014, 26, 3879-3884. [CrossRef] [PubMed]

99. Bouhlala, M.A.; Kameche, M.; Tadji, A.; Benouar, A. Chitosan hydrogel-based electrolyte for clean and biodegradable batteries: Energetic and conductometric studies. Phys. Chem. Liq. 2018, 56, 266-278. [CrossRef]

100. Jia, X.T.; Wang, C.Y.; Ranganathan, V.; Napier, B.; Yu, C.C.; Chao, Y.F.; Forsyth, M.; Omenetto, F.G.; MacFarlane, D.R.; Wallace, G.G. A Biodegradable Thin-Film Magnesium Primary Battery Using Silk Fibroin-Ionic Liquid Polymer Electrolyte. ACS Energy Lett. 2017, 2, 831-836. [CrossRef]

101. Jia, X.T.; Wang, C.Y.; Zhao, C.; Ge, Y.; Wallace, G.G. Toward Biodegradable Mg-Air Bioelectric Batteries Composed of Silk Fibroin-Polypyrrole Film. Adv. Funct. Mater. 2016, 26, 1454-1462. [CrossRef]

102. Huang, X.Y.; Wang, D.; Yuan, Z.Y.; Xie, W.S.; Wu, Y.X.; Li, R.F.; Zhao, Y.; Luo, D.; Cen, L.; Chen, B.B.; et al. A Fully Biodegradable Battery for Self-Powered Transient Implants. Small 2018, 14, e1800994. [CrossRef] [PubMed]

103. Lu, L.Y.; Yang, Z.J.; Meacham, K.; Cvetkovic, C.; Corbin, E.A.; Vazquez-Guardado, A.; Xue, M.T.; Yin, L.; Boroumand, J.; Pakeltis, G.; et al. Biodegradable Monocrystalline Silicon Photovoltaic Microcells as Power Supplies for Transient Biomedical Implants. Adv. Energy Mater. 2018, 8, 1703035. [CrossRef]

104. Hwang, S.W.; Huang, X.; Seo, J.H.; Song, J.K.; Kim, S.; Hage-Ali, S.; Chung, H.J.; Tao, H.; Omenetto, F.G.; Ma, Z.Q.; et al. Materials for Bioresorbable Radio Frequency Electronics. Adv. Mater. 2013, 25, 3526-3531. [CrossRef] [PubMed]

(C) 2018 by the authors. Licensee MDPI, Basel, Switzerland. This article is an open access article distributed under the terms and conditions of the Creative Commons Attribution (CC BY) license (http:// creativecommons.org/licenses/by/4.0/). 